
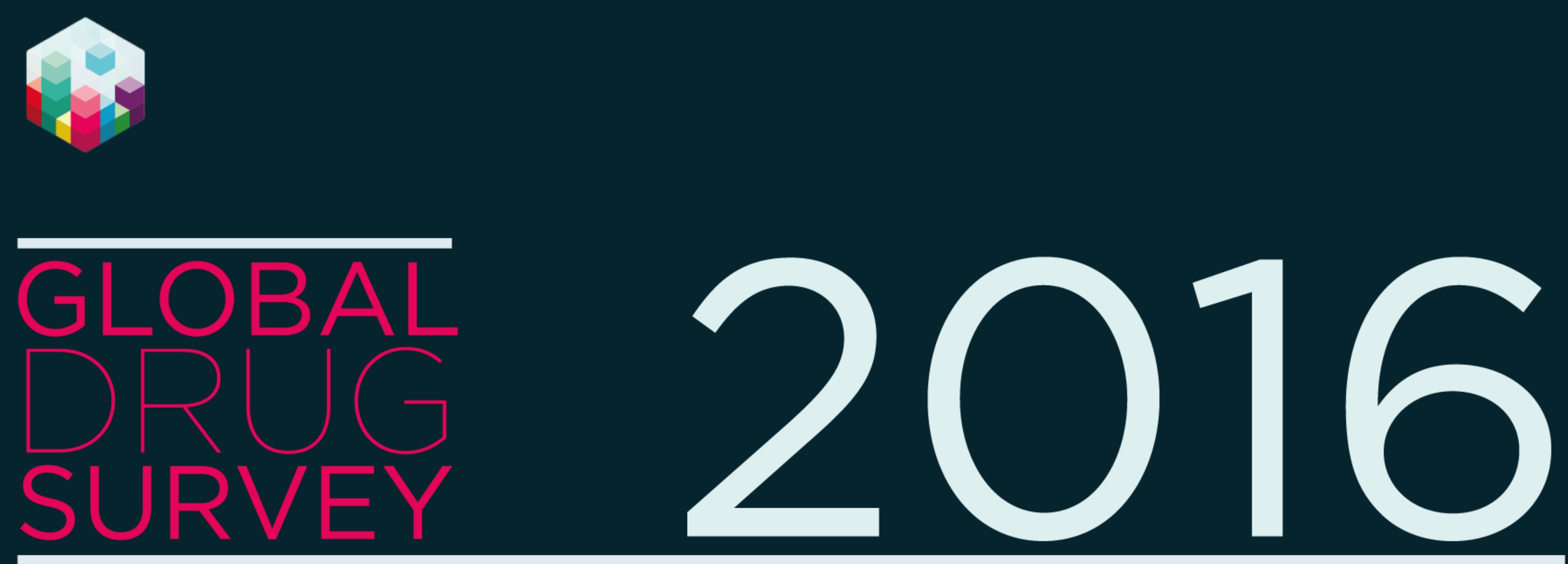

What we learned from GDS2016

An overview of our key findings

Dr Adam R Winstock, Dr Monica Barrett, Dr Jason Ferris \& Dr Larissa Maier The GDS Core Research Team 


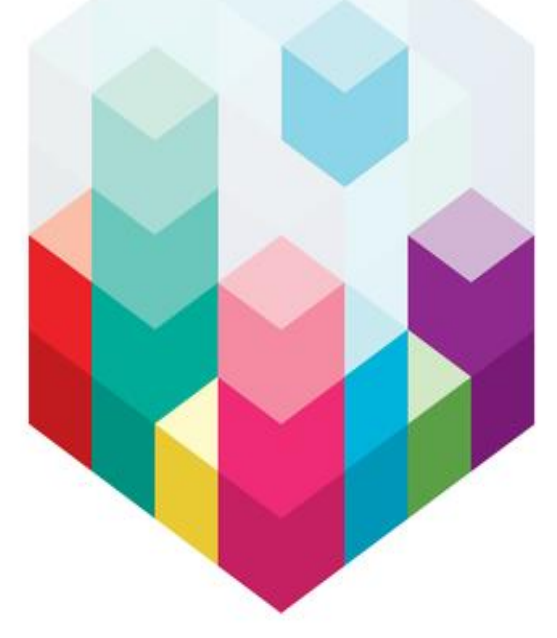

\section{GLOBAL DRUG SURVEY}

\section{еГОВ}

WE RUN THE BIGGEST DRUG SURVEY IN THE WORLD

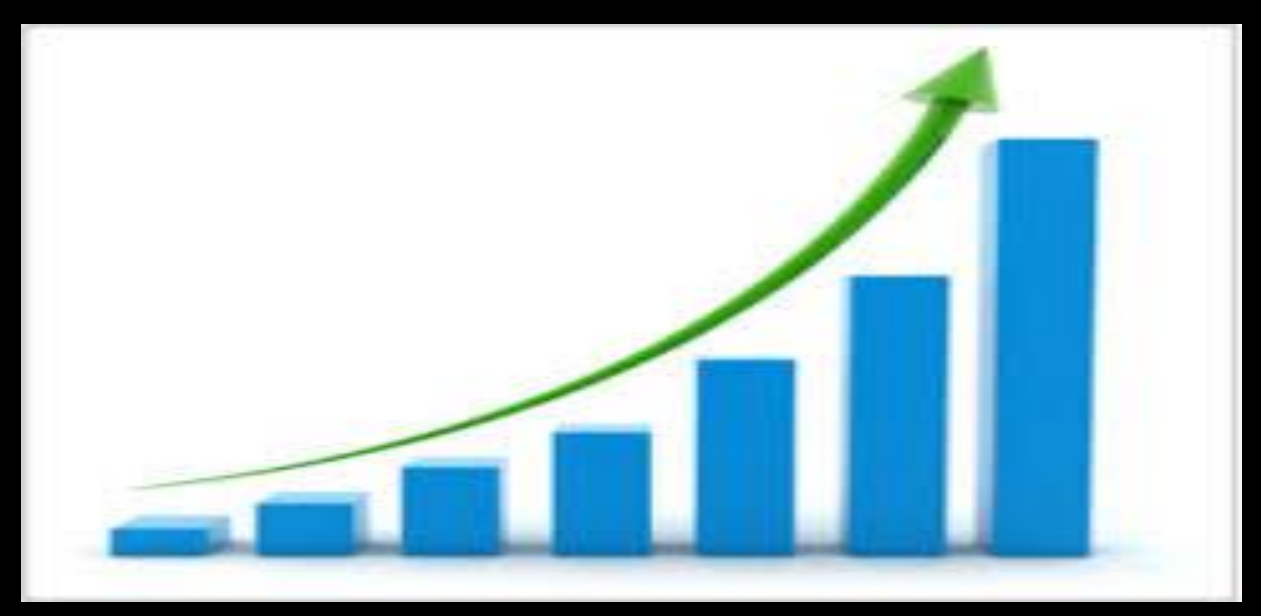

- GDS 2012: 15,500

- GDS 2013: 22,000

- GDS 2014: 77,000

- GDS 2015:100,000

- GDS 2016: 100,000

- GDS2017: target 250K

If you want to join e-mail us at info@globaldrugsurvey.com 
Global Drug Survey (GDS) runs the world's biggest annual drug survey.

\section{A total of $101,313 *$ people from over 50 countries participated in GDS2016}

*Data analysis was conducted on out on 97,000 for these preliminary analyses.

About

GDS is an independent global drug use data exchange hub that conducts university ethics approved, anonymous on-line surveys. We collaborate with global media partners who act as hubs to promote our work.

GDS is comprised of experts from the fields of medicine, toxicology, public health, psychology, chemistry, public policy, criminology, sociology, harm reduction and addiction. We research key issues of relevance and importance to both people who use drugs and those who craft public health and erug policy.

\section{Using and reporting the data}

In all copy related to the data provided the study should be referred to as Global Drug Survey 2016 (GDS2016)

\section{Mission}

We aim to make drug use safer regardless of the legal status of the drug by sharing

information in a credible and meaningful way.

Our last 3 surveys, run at the end of 2013, 2014 \& 2015 received almost 300,000 responses.

Over the last decade GDS has successfully supported the widespread dissemination of essential information both to people who use drugs through our media partners and to the medical profession through academic papers presentation at international conferences and, expert advisory meetings
GET FREE APPS AND ADVICE

TO MAKE DRUG USE SAFER

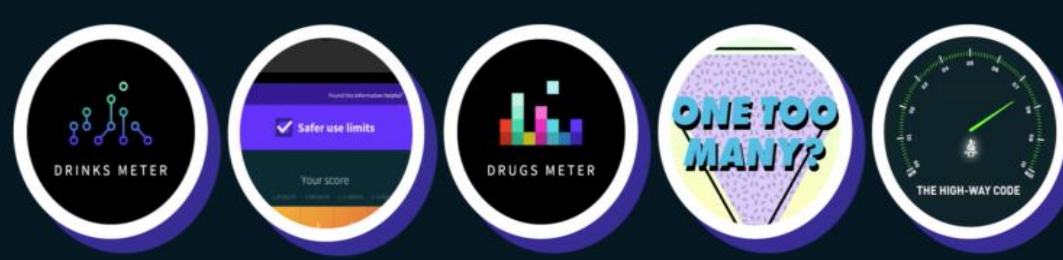

REGARDLESS OF THE LEGAL STATUS OF THE DRUG
www.youtube.com/user/GlobalDrugSurvey www.globaldrugsurvey.com

www.drinksmeter.com

www.drugsmeter.com

www.saferuselimits.com

www.onetoomany.com

www.globaldrugsurvey.com/brand/the-highway-code/ 


\section{Just how generous people were with their time?}

We estimate that over the duration of the study (Nov 15 - Jan 16) over 100,000 people spent in excess of 3.5 million minutes OR

58,000 hours OR

2400 days OR

350 weeks OR

6.5 years sharing their drug use experiences with us. So a HUGE thanks to you all. GDS does not exist without you.

GDS is the world's biggest annual drug survey. Our last survey, GDS2016, ran for 6 weeks at the end of 2015, was translated into 10 languages and received $>100,000$ responses from around the world. Over the last 3 years we have obtained data from almost 300,000 people. By the end of 2016 we estimate our global database will be in excess of 600,000 .

GDS has expanded this year, with an increasing number of countries, groups and individuals joining our network. We acknowledge the overwhelming support and encouragement we continue to receive from our global media partners, academic network and many harm reduction groups around world.

\section{Thank you to everyone who took part}


It is important to understand what GDS can and cannot do when interpreting our findings. Don't look to GDS for national estimates of drug use. GDS is designed to answer comparison questions that are not dependent on probability samples. GDS acknowledges that when compared with traditional epidemiological criteria for a good public health surveillance system, our approach has significant limitations. GDS utilizes non-random, opportunistic sampling methods to recruit very large numbers of people who use drugs. The recruitment window is brief with the survey active for only 6 weeks. In 2016, there was an exception to this due to the saddening events in Paris, France that coincided with the recruitment period of GDS. The sample representativeness is limited by response bias, meaning there will be inherent differences between those who participate and those who do not. This survey is only available on-line and will therefore tend to miss those without easy online access and those with lower levels of literacy.

Throughout this report we provide some comparisons on some key areas that may be of interest to readers of your publications. Because the samples we have obtained from different countries vary considerably in size, demographics and other characteristics, such comparisons have to be treated with caution. The limitations in cross country comparisons will be more marked for some results than others, particularly in countries with small numbers.

The GDS database is massive but its non-probability sample means analyses are suited to highlight differences among user populations. GDS is thus best suited to answer comparison questions that are not dependent on probability samples. The GDS sample allows you to effectively compare population segments - young, old, males, females, gay, straight, clubbers, thin people, obese people, vegetarians, those with a current psychiatric symptoms and diagnoses, students, northerners, southerners. GDS also explores the experience of particular drugs on users, such as seeking medical attention and/or the desire to change consumption patterns. GDS can help add numbers and depth to the findings of more rigorous, though less detailed and smaller, survey findings. GDS reaches hidden, sentinel and hard to reach populations. GDS puts you on top of emerging drug trends in your country and major cities 


\section{WHAT GDS WON'T DO FOR YOU}

- Don't look to GDS for national estimates of drug use prevalence .

- GDS is designed to answer comparison questions that are not dependent on probability samples.

- GDS database is huge but its nonprobability sample means analyses are suited to highlight differences among user populations.
WHAT GDS WILL DO FOR YOU

- GDS is an efficient approach to gain content rich data that explores diverse health outcomes associated with the use of drugs and alcohol across the population of your country.

- GDS recruits younger, more involved drug using populations.

- We spot emerging drug trends before they enter into the general population

- Our data is $<6$ months old

- GDS helps you better understand the quantitative dynamics of personal decision-making about drug use, detects regional differences in patterns of drug use and related harm and informs novel interventions.

- Provides current data on the patterns of use, harms, health and well-being experienced by the full spectrum of users. 


\section{WHERE IN THE WORLD}

Norway

Canada

Mexico

Belgium

Brazil

Portugal

Sweden

Scotland

Republic of Ireland

Denmark
$1.5 \%(1,461)$

$1.5 \%(1,297)$

$1 \%(1,203)$

$1 \%(1,027)$

$1 \%(1,012)$

$1 \%(1,008)$

$1 \%(706)$

$1 \%(647)$

$1 \%(707)$

$0.5 \%(296)$
Hungary

Spain

Colombia

Austria
$5 \%(4,931)$

$4 \%(3,858)$

$3 \%(3,189)$

$3 \%(3,071)$

$3 \%(2,520)$

$2 \%(2,095)$

$2 \%(2,055)$
"Probability based surveys tell you about the size of the drug use problem in your country. GDS tells you what to do about it" Dr Adam Winstock 


\section{GDS2016.5 A mini 5 minute launch survey}

Following our global media report release on June 14th 2016 we will be running a 5 minute survey exploring 4 areas in depth as part of GDS2017. These are:

1) How have psychedelics changed your life?

2) What drugs have you ever 'vaped'?

3) Would you use drug checking facilities if you had them available?

4) What do you do when your mate collapses/passes out?

5) Please promote this using your networks and we'll share the results with you in November 2016.

6) The link will go live on June $14^{\text {th }} 2016$ at www.globaldrugsurvey.com/GDS2016.5

\section{GDS2017 areas of focus - launching November 2016}

GDS has invested heavily this year in new design and technology. GDS2017 can be easily completed on phones and tablets; it will also allow continuous data submission. We will have a short core survey that will take 20 minutes to complete plus 4 specialist areas that people can opt into if they chose.

GDS2017 will focus on 4 areas:

1) How psychedelics change people and are used by people for different functions from micro-dosing LSD to the commercialization of Ayahausca.

2) While vape technology may be a common way to use nicotine and increasingly cannabis, the interaction between this technology and drugs is only just beginning. GDS2017 will explore how 'vaping' changes the drug experience and what other drugs people are choosing to use this way

3) How people use MDMA to maximize pleasure and minimize the risk of problems and how this once archetypal dance drug has left the dance floor for people's living rooms and dinner parties

4) Drug tourism - people travel the world to take drugs - but does their consumption and risk vary when they leave their own backyard? GDE20J7 8 will tell the real story of drug use abroad. 
If you want to get a full downloadable copy of our report please send an e mail request to info@globaldrugsurvey.com

As a taster of the please see the next few slides 
Key findings from the Global Drug Survey2016 (data collected Nov 15-Jan 16)

More people shopping on the dark net, more people using MDMA \& experiencing harm, synthetic cannabinoids the most dangerous drugs in the world.

Novel Psychoactive Substances (NPS) Trends in the UK - most people buy NPS on-line

UK has highest rate of last year NPS purchase of any GDS country (11.6\% of UK sample)

GDS2016 reports increase in UK last year purchase of NPS after falling rates over last 4 years

Decline in high street NPS purchases from 46.3\% in GDS2014 to 34.6\% in GDS2016.

$58 \%$ of those reporting buying NPS last year did so on-line.

3 times more likely end up seeking emergency medical treatment with NPS than traditional drugs

\section{Synthetic Cannabinoids (SCs) and A\&E}

Synthetic cannabinoids more likely to lead to emergency medical treatment than any other drug 1 in 8 of those using weekly or more often reported seeking emergency medical treatment (3.5\% of all users)

Overall risk of seeking emergency medical treatment when using SCs is 30 times greater than skunk

Over half of those using more than 50 times in last year who tried to stop reported withdrawal symptoms 


\section{The dark-net rising}

- Globally almost in 1 in 10 participants (9.3\%) reported ever buying drugs off the dark-net with those reporting last year dark-net purchase rising from $4.5 \%$ to $6.7 \%$.

- MDMA, cannabis, new or novel substances (including 2C-B and DMT) and LSD are the drugs most commonly bought

- $5 \%$ of respondents stated that they did not consume drugs prior to accessing them through dark-net markets

\section{The worst time to be using MDMA in a generation}

- Increase in use of both MDMA and cocaine over the last 3 years.

- Concerns over high dose MDMA pills leading to increased risk of acute harm

- 4-fold increase in British female clubbers seeking emergency medical treatment in last 3 years. Women 2-3 more likely to seek emergency treatment than men

- UK users take more MDMA in a night than anyone else (almost half a gram)

- Most people use less than 10 times per year 


\section{No Laughing Matter}

Biggest study of nitrous oxide use ever

Increasing rates of use in the UK and globally nitrous oxide is now ranked the $7^{\text {th }}$ most popular drug in the world.

$10 \%$ of users worried about impact of mental / physical health

$4 \%$ reporting symptoms of nerve damage due to vitamin B12 deficiency

\section{Drinkers}

One third of drinkers would like to drink less in the coming year yet only $10 \%$ on average would like help to do so. www.drinksmeter.com and www.onetoomany.co might help people drink less.

Spirits best avoided on night out 


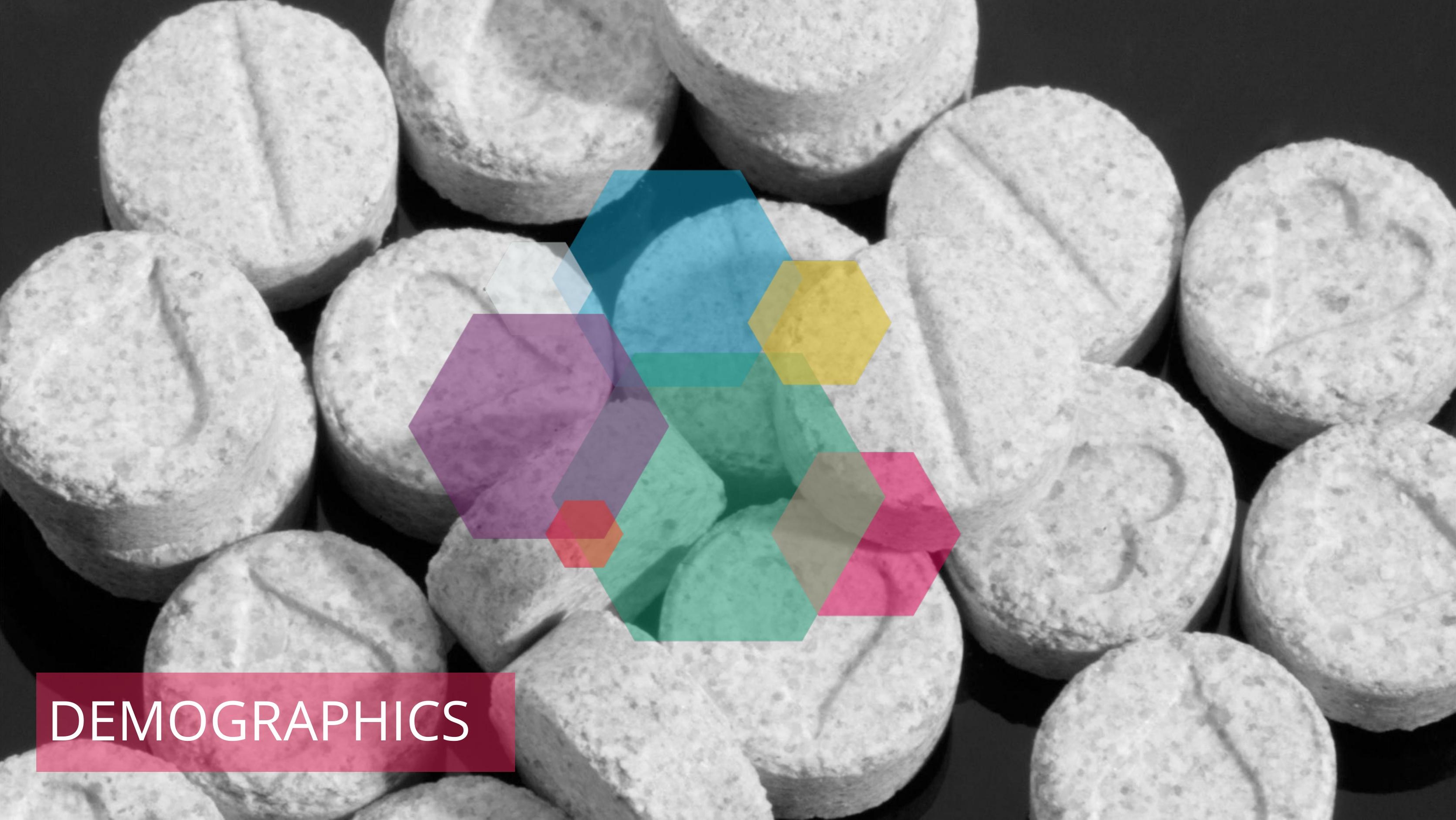




\section{Who took part?}

- Two thirds were male, mean age 28.7 years, $47 \% 24$ or younger, $23 \%$ $>35$ years

- In terms of education just over 1/3 had a degree, 2/3 paid employment, with $40 \%$ in full or part time education

- $89 \%$ white

- $83 \%$ heterosexual, $10 \%$ bisexual, 5\% homosexual.

- $10 \%$ vegetarian.

- The mean BMI of participants was 24.2

- $1 / 3$ live with their partners, $25 \%$ with their parents,

- $75 \%$ from city/urban areas, $21 \%$ regional and $4 \%$ from remote areas

- $60 \%$ exercised at least weekly, $62 \%$ clubbing at least every 3 months,
Summary of ever and last year drug experience by legal status and IV use (global sample $\mathrm{M}+\mathrm{F}$ )

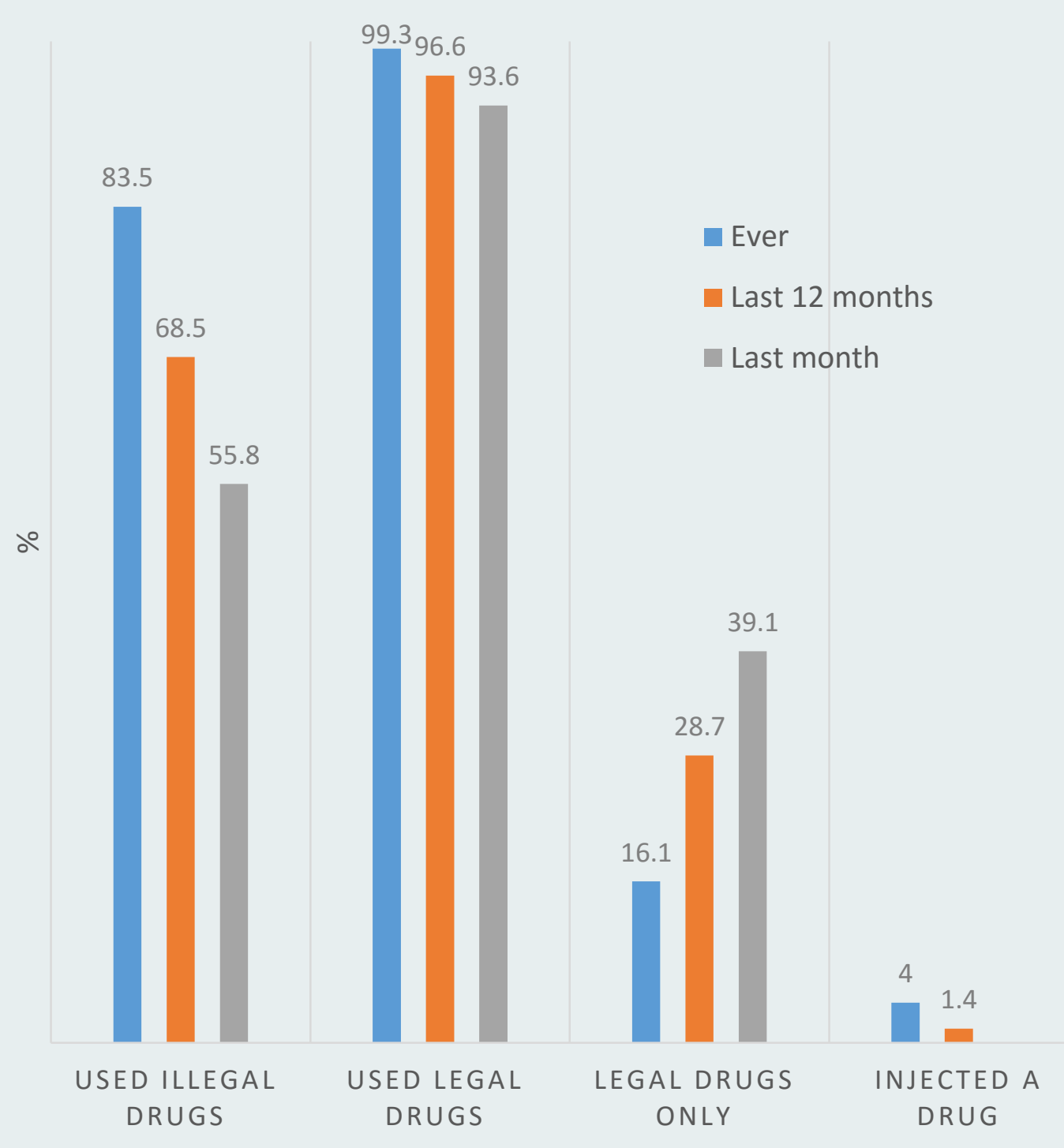




\section{$\%$ of GDS global sample reporting use of different drugs in last 12 months}

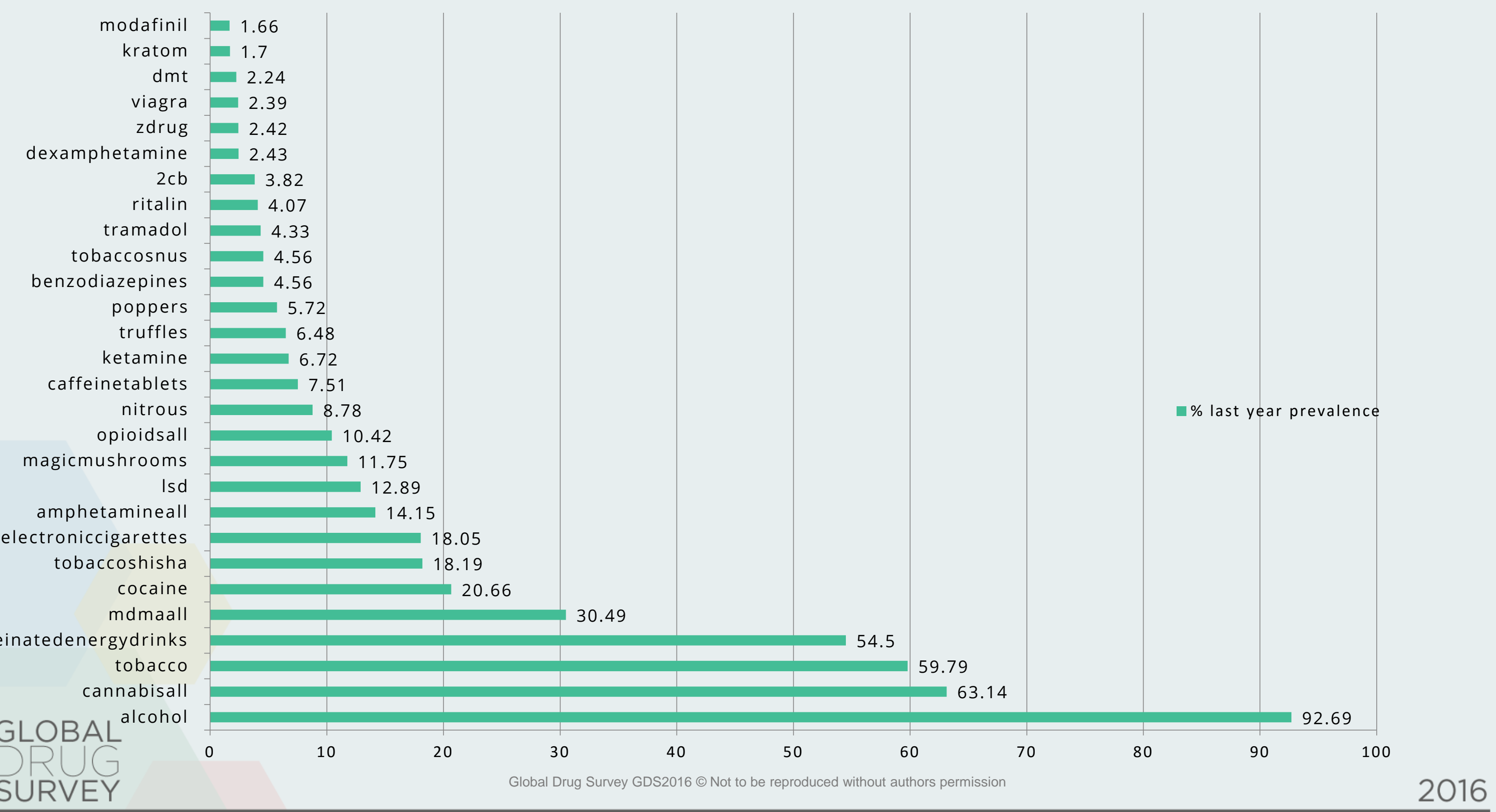




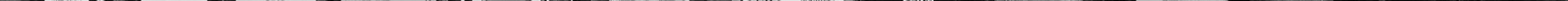




\section{Alcohol}

Ireland got stiff competition this year, when it came to which country has the highest proportion of people who want to drink less. It was pipped to the post by Mexico (see next slide), where just under half of all drinkers said they would like to drink less next year. Third and fourth place went to Australia and Norway respectively, where over $40 \%$ reported a desire to drink less.

The Dutch and the Portuguese seemed least interested in cutting down, with only one in four indicating they'd like to do so.

In terms of acute harms, Ireland and Norway came in joint second to Scotland, where $2.4 \%$ of drinkers reported seeking emergency medical treatment following drinking.
$\%$ of drinkers reported seeking emergency medical treatment after drinking

Global EMT Ratı was $1.1 \%$

2.5

0.5

0

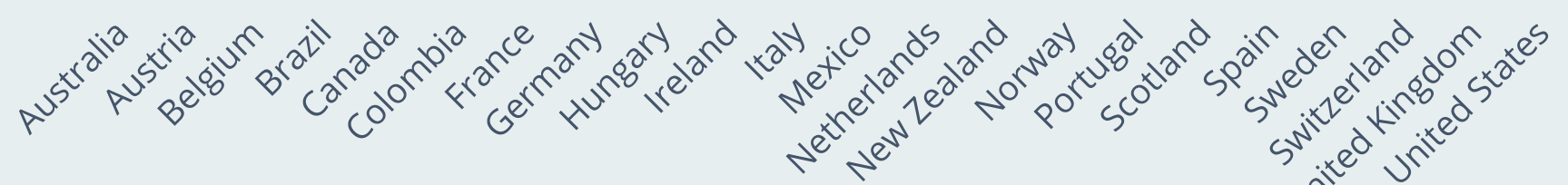

1.5

1.3
1.9

2.4

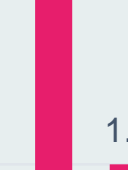




\section{Are all alcoholic beverages the same?}

Many countries have beverage mythologies right at their cultural core. These myths have little basis in scientific fact. From a chemist's perspective alcohol is a naturally occurring group of organic compounds, predominantly in the form of ethyl alcohol or ethanol. Ethanol increases the influence of a chemical transmitter in the brain called GABA that slows or quietens brain activity, hence we call alcohol a depressant. While alcohol also has a host of other subtle effects on the brain, the active ingredient is always ethyl alcohol. So no matter how you make your alcohol, it its always ethyl alcohol that gets you drunk. While the choice of source product and the difference between fermentation and distillation determine whether you make beer, cider, wine or spirits, the variation in taste and smell is largely due to the contribution of various congeners - chemicals which include acetone, acetaldehyde, esters, fusel alcohols and aldehydes.

These congeners may contribute to the difference in possible effects. Acetaldehyde is a breakdown product of alcohol that contributes to hangovers. Darker beverages such as red wine, scotch and brandy contain a higher percentage of congeners. Studies are inconsistent, but many report that the darker the drink, the worse the hangover.

GDS2016 aimed to find out whether different drinks affect people differently in a consistent manner around the world. Before we take a look at the results let's quickly review the possible scientific explanations for what we might find.

- It might be that certain drinks tend to get drunk in different ways, meaning that it's easier to drink more alcohol in some forms than others.

- It might be that some drinks are more likely to be drunk in certain environments or on different occasions

- It might be that some people drink certain drinks when they are feeling in particular moods

- It might be that certain drinks are more likely be drunk by certain people

- It might be that some drinks are drunk with certain mixers that alter mood or behavior (e.g. energy drinks)

- It might be that people try to make sense of what has happened after the event (known as 'effort after meaning) For example 'I ended up with that turd in my pocket because of the brandy, you know what it does to me...), i.e. its an excuse that people can pull out that might avoid them admitting they just drunk too much - It might be all be nonsense

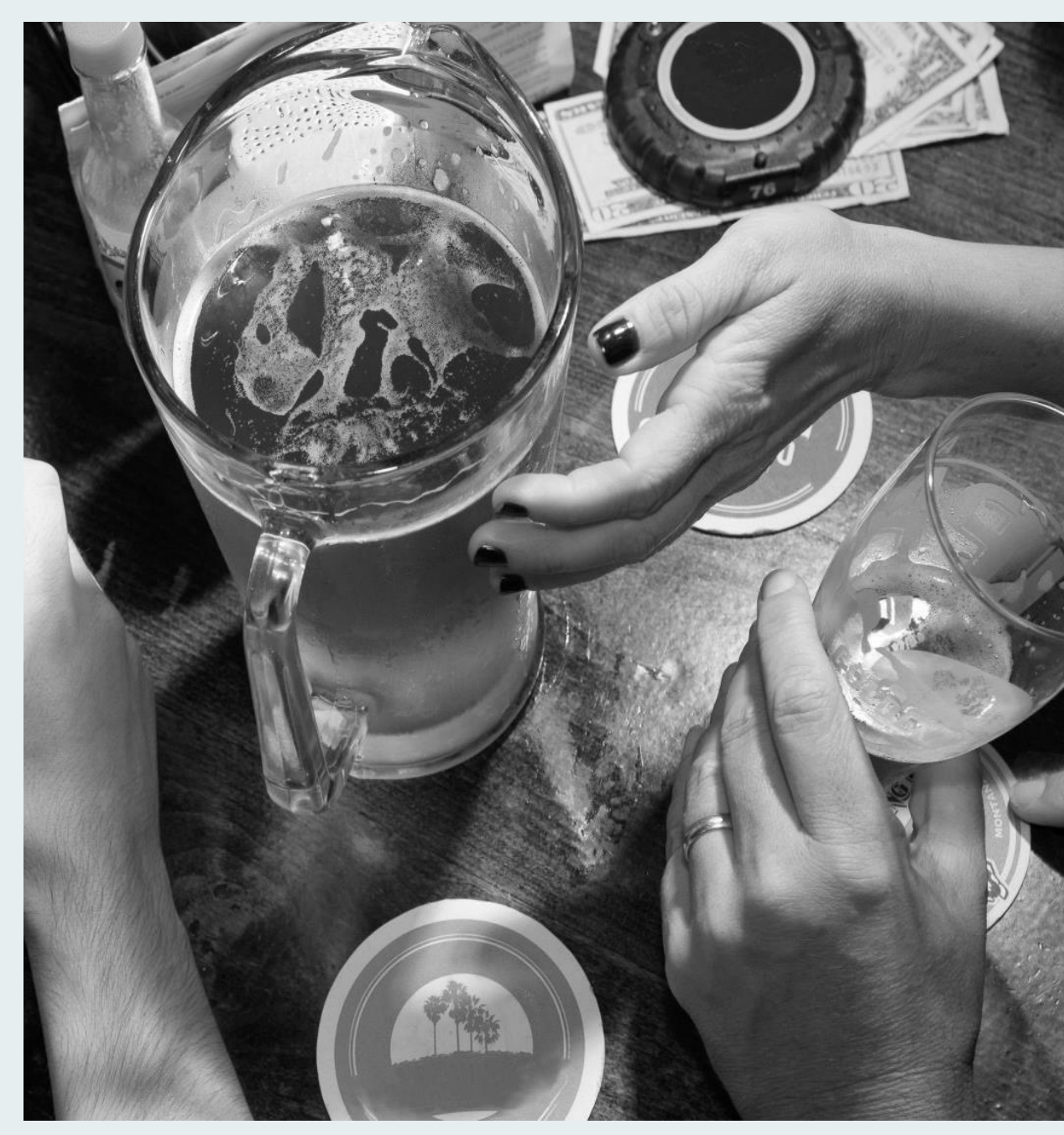

\section{GLOBAL


Type of drink that gives the worst hangover

\section{(\%) (GLOBAL)}

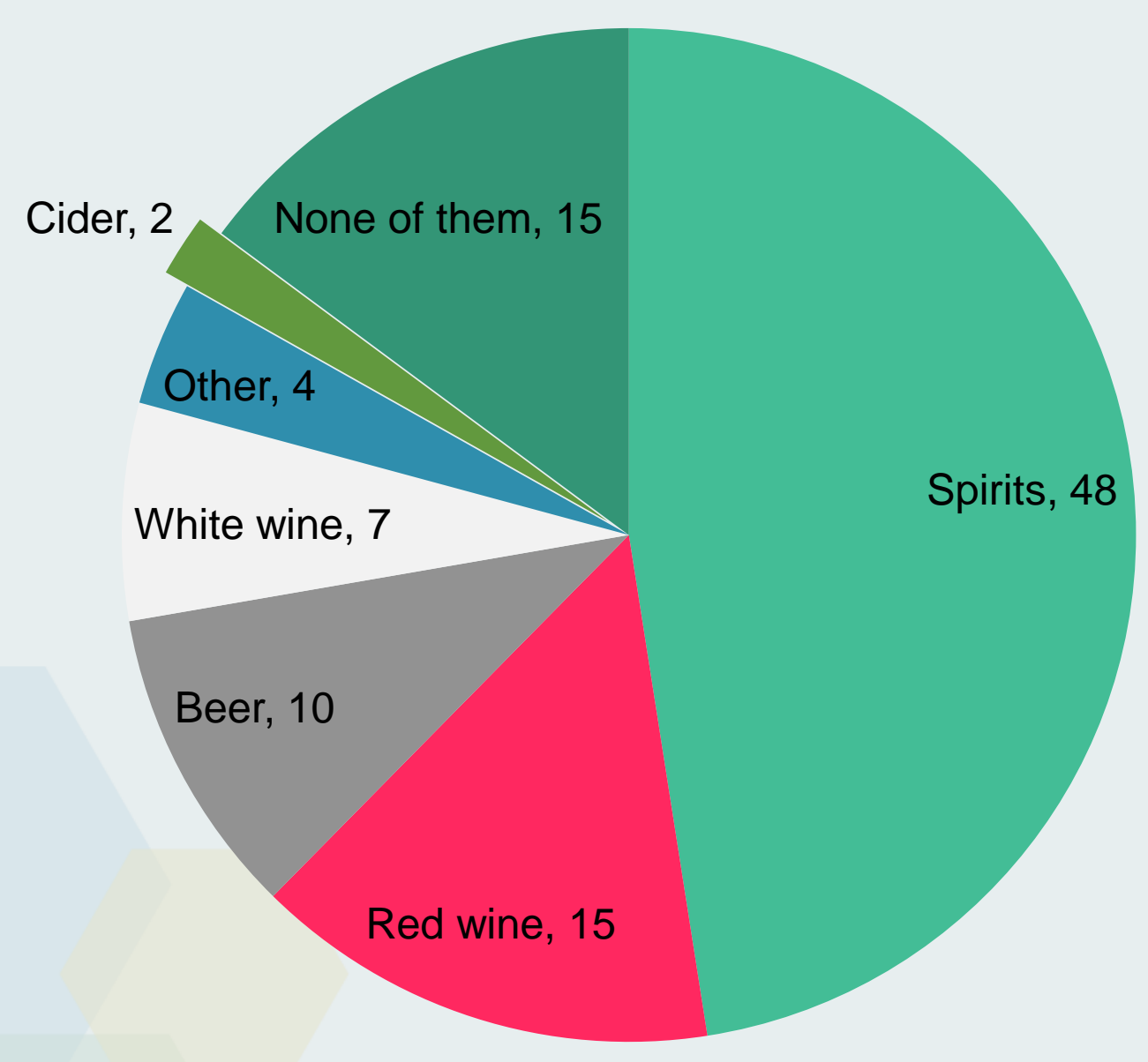

With a third of all drinkers on average saying they would like to think less and others who probably need to, GDS is pleased to remind you of our fabulous Drinks Meter app, free on the app stores or at www.drinksmeter.com. V3 is out this summer and we are now offering health region and local service versions to deliver IBA on tablets and online in multiple languages.

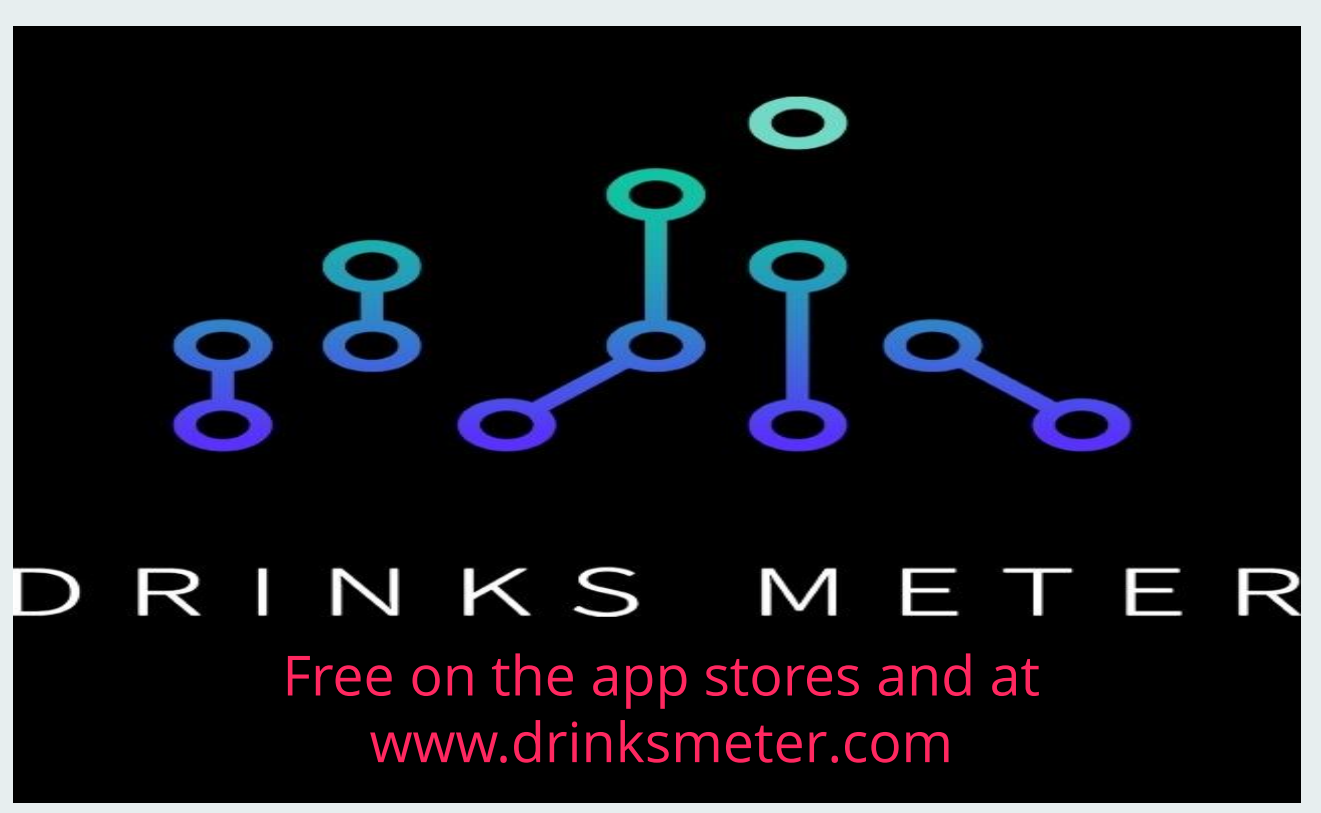


Despite some considerable national variation, it seems that spirits are the type of alcohol most commonly drunk when away from home and also rated most likely to make you feel energised, confident and sexy. Inconsistently, spirits were also rated as most likely to make you feel restless, tearful and ill (including most likely to give you a hangover). Beer was voted as most likely to make you feel relaxed and red wine topped the list for making you Feel sleepy. The polarizing effects of spirits are most likely to be a consequence of dose. Low levels of alcohol can cause disinhibition and reduce mild anxiety making people feel more confident and outgoing. Low levels of alcohol might also be felt as stimulating by some users, though in other cases the stimulation will come from the caffeinated mixers commonly used to dilute spirits (colas and energy drinks). Higher doses of alcohol can result in nausea, dizziness, excessive sweating, emotional dysregulation people become inexplicably angry, sad, hostile, tearful etc.) and of course the more you drink the worse your hangover.

So a lot of the problems caused by sprits might come down to the fact that they are more difficult to titrate (drinking to a level that gets the effect you want without over shooting it) than beer or wine.
Titration with spirits is difficult for three main reasons. Firstly, since they are the most potent form of alcohol, you can consume more alcohol more quickly when drinking spirits that other types of beverage. It's easy to get drunk too quickly on spirits and once you're drunk making smart decisions about everything becomes difficult. Secondly, spirits with alcohol content above 20\% ABV are difficult to absorb and at $40 \%$ ABV your stomach stops emptying. What this means is that despite having drunk as much as you need to, you might not yet feel the full effects of what you have drunk. People then carry on drinking thinking 'I'm fine', until 'boom' the alcohol that has been sitting in your stomach gets absorbed and you end up way more drunk that you planned. The third reason that spirits are difficult to titrate is because of the wide variation in serving size from shots, to doubles in mixers to cocktails. It can be almost impossible to keep track of how much you have had.

You can end up cool and sexy or pathetic and passed out on any form of alcohol. If all the above is true, there appear to be advantages to avoiding spirits. This is not because of the 'alcohol' necessarily having different effects, but because spirits are highly concentrated, hard to titrate and keep track of, and they can fool your body into thinking you have not yet drunk 'enough', all of which GDS would consider good reasons to avoid spirits. 


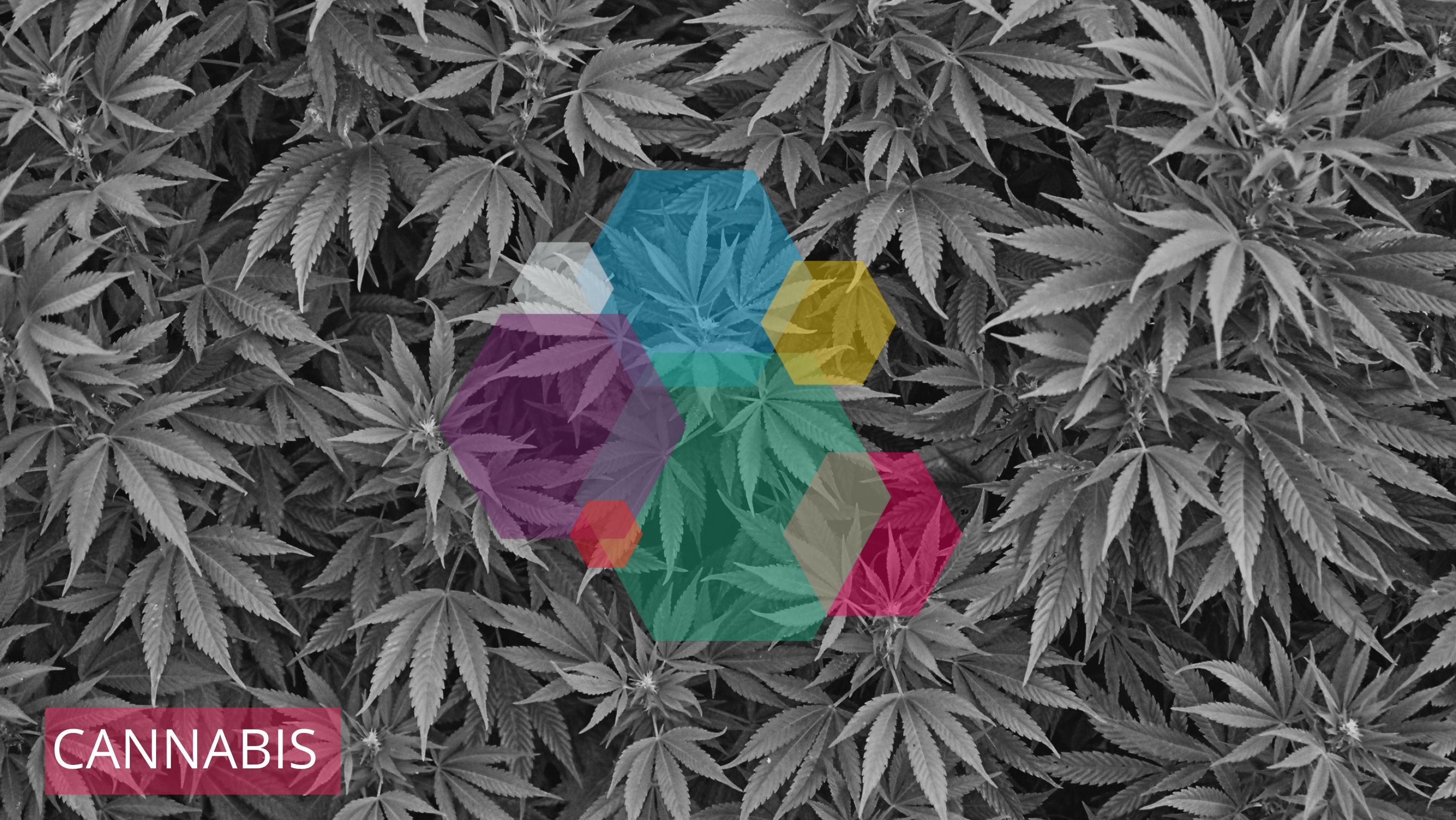




\section{Global comparison of preferred cannabis preparations around the world}

We think things are changing, possibly for the better in some respects. First, GDS data seem to suggest that high potency herbal cannabis is no longer the default or preferred preparation around the world.

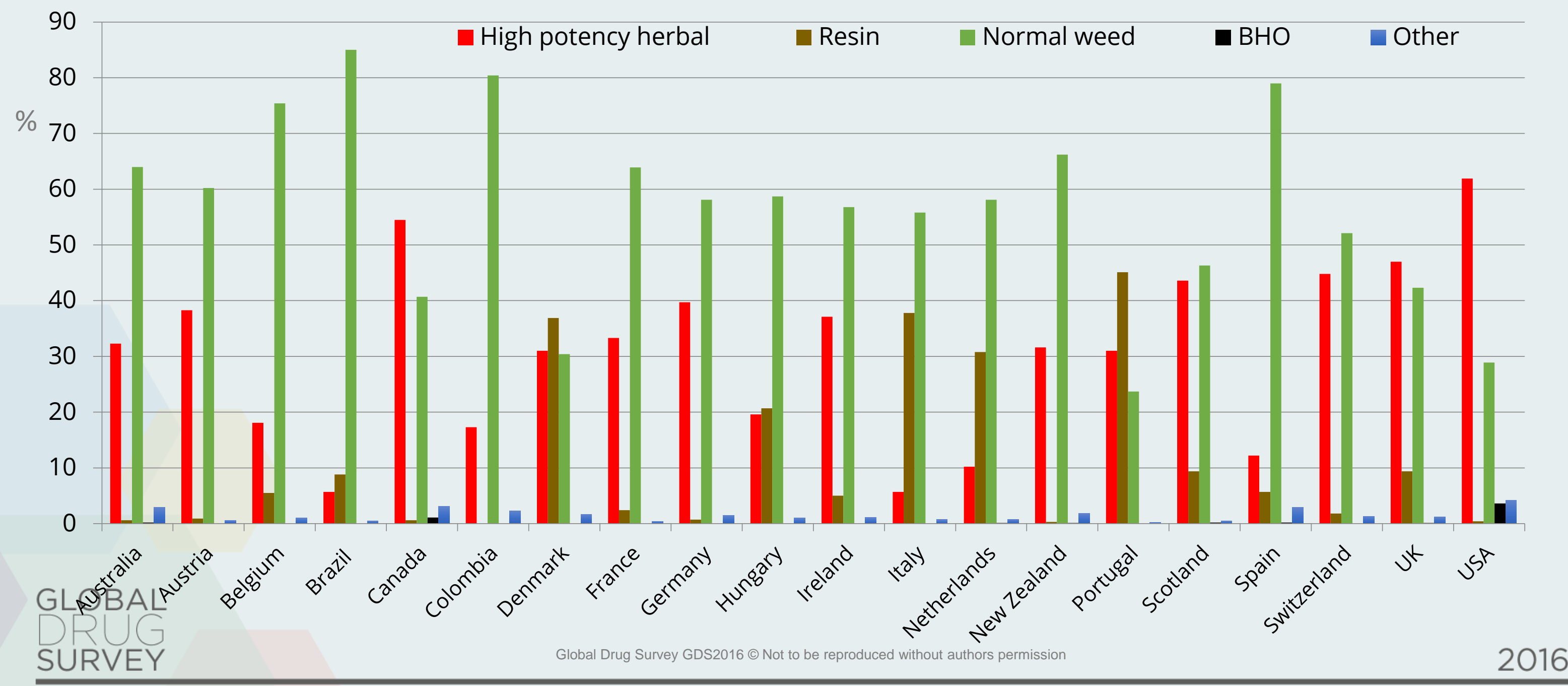


We remain surprised at just how many cannabis users report seeking emergency medical treatment (EMT) in the previous 12 months. $1.2 \%$ of over 45,000 cannabis users who took part in GDS2016 reported such an episode. Although seeking emergency medical treatment is not the same as having a bad time on a drug, or even needing serious medical intervention, it does give an indication of the prevalence and nature of acute problems following the use of cannabis.

The most commonly implicated was high potency cannabis, though every type was represented.

The rates of seeking EMT varied widely between countries. It was surprising that Portugal where resin predominates and Colombia and Brazil where natural weed is most common, reported such high rates. GDS will be looking at just who was most at risk of seeking acute treatment in the coming months (e.g. less experienced users, heavier users, those with mental illness etc.)

\section{GLOBAL}

Overall $1.2 \%$ of cannabis users - sought Emergency Medical Treatment (EMT) in the last 12 Months

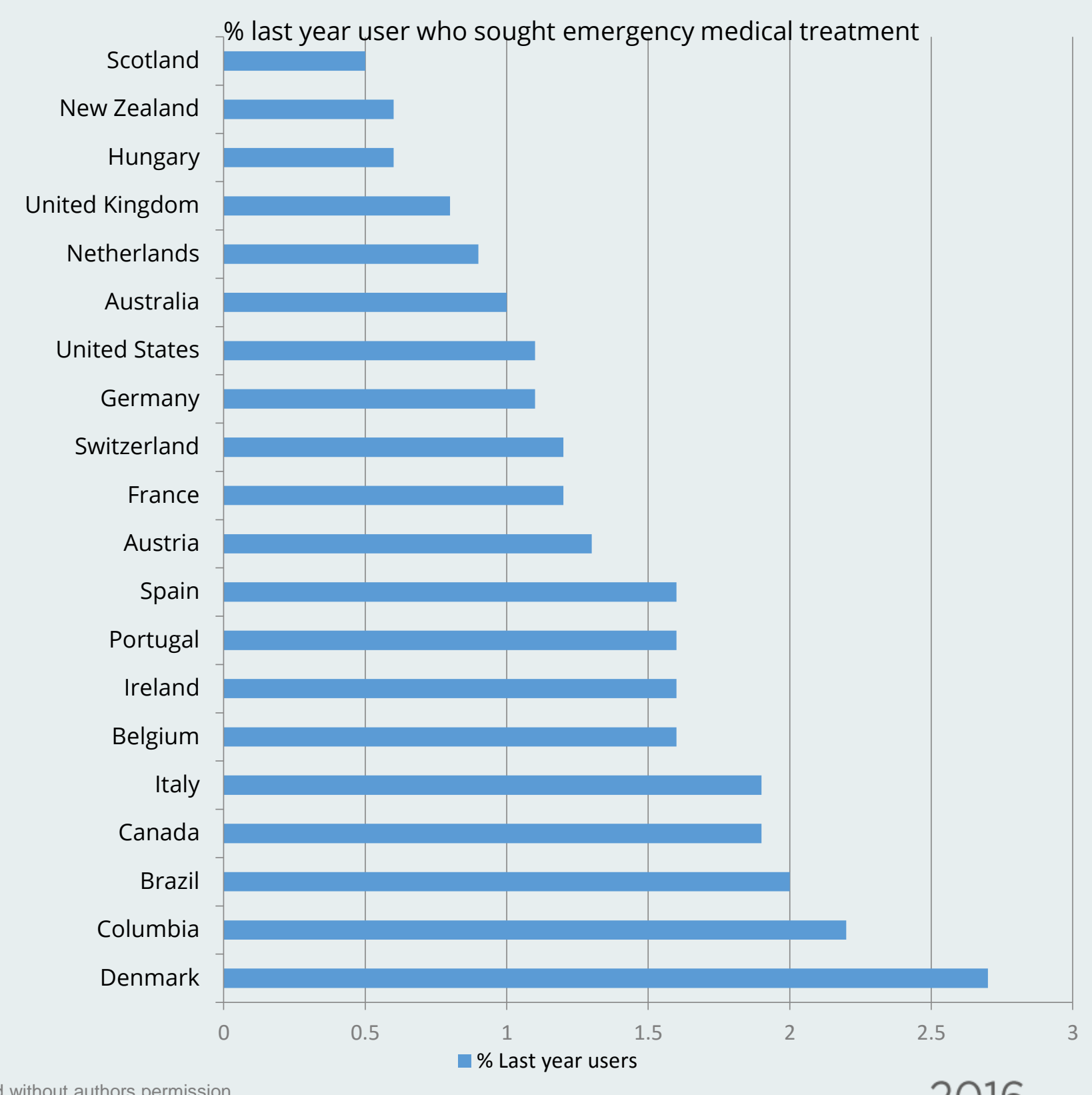


1 in 3 users wants to use less, $10 \%$ are dependent and $1 \%$ need to Helping doctors make better decisions visit the emergency room each year. This means a lot of people who are using a drug that we might think of as not that risky, are experiencing difficulties. Whilst www.drugsmter.com can be a great source of feedback, we thought some guidelines might help so we created them at www.saferuselimits.co

\section{A Research Education News Comment}

Search all BMJ comment articles From $1840 \mathrm{~V}$ Jan
Cannabis WON'T harm your health as long as you stick to one small joint a week, scientists claim

By Madlen Davies for MailOnline 13:00 18 Jun 2015, updated 14:04 18 Jun 2015

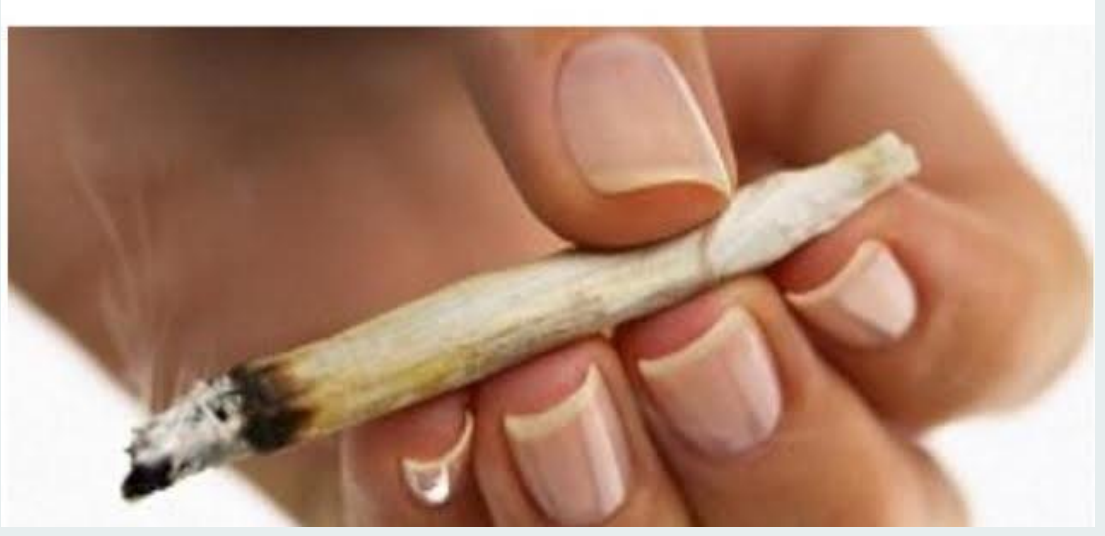

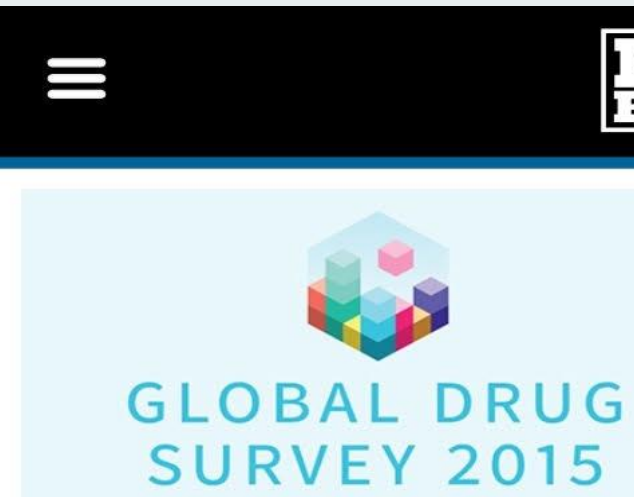

Global Drug Survey launches world's first Safer Use Limits Guidelines for Cannabis

The Hot Press Newsdesk

It's Ireland's illegal drug of choice, but how is cannabis impacting on your health? 


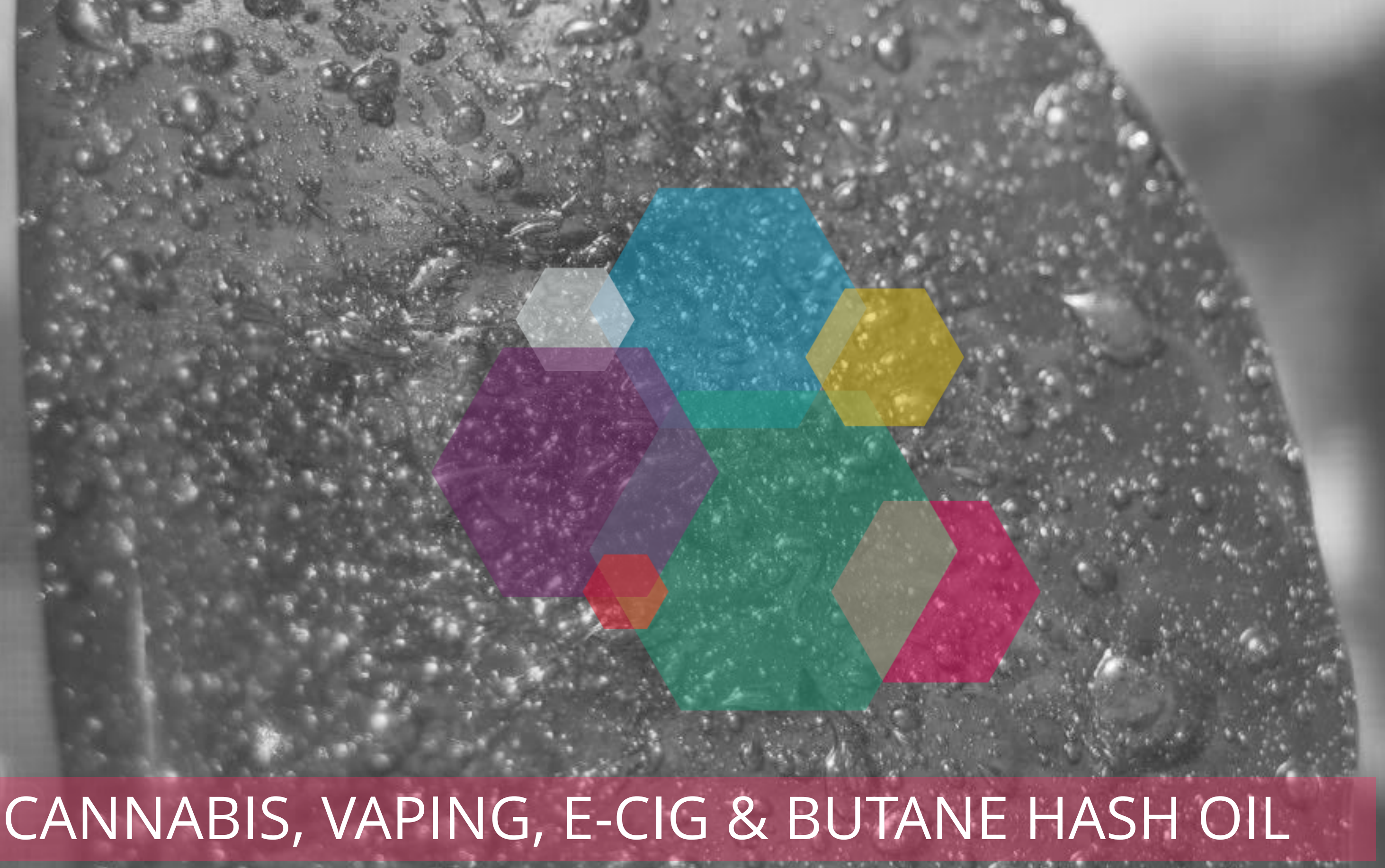


$\mathrm{BHO}$ continued to show its rising popularity in the US (where just over a third of cannabis users reported use of BHO) and Canada. The most striking changes compared to last year's findings were the increase in the recent cannabis users reporting the use of $\mathrm{BHO}$ (6.4\% up from $4.2 \%$ last year) and the significant drop in people using it with joints in tobacco and the marked rise in people using bongs to use BHO. Overall the data from GDS2015 and GDS2016 suggests BHO typically gets people more stoned, more quickly and for longer than high potency herbal cannabis. The worry is that people also build up tolerance more quickly and may be more at risk of acute unwanted experiences. These issues will need to be balanced against the potential health benefits of promoting non-tobacco routes of administration. GDS repeats its request to manufactures made last year to produce and promote more balanced BHO oils (THC / CBD ratio closer to 2 or 3:1) and for public health agencies to encourage the use of vape pens and other non-tobacco related routes of use.

With over a third of our last year users reporting use on 100 days or more in the last year and too many people smoking it and mixing it with tobacco, GDS wants to remind people about our free cannabis tools, the drugs meter (free on google play and www.drugsmeter.com) and the world's first ever safer use limits guide at www.saferuselimits.co. We have data to produce these safer use limit guides for MDMA, cocaine and ketamine - so if anyone wants to fund these please let us know!

\section{GLOBAL}




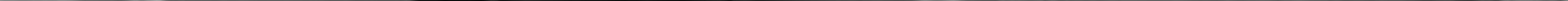


$\%$ of last year users of each substance who sought Emergency Medical Treatment following the use of that substance

4.5

4

3.5

3

2.5

2

1.5

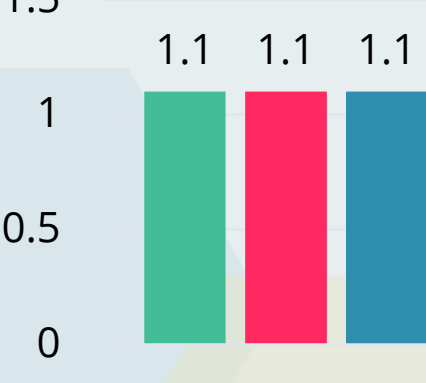

Alcohol

$\mathrm{N}=90 \mathrm{~K}$

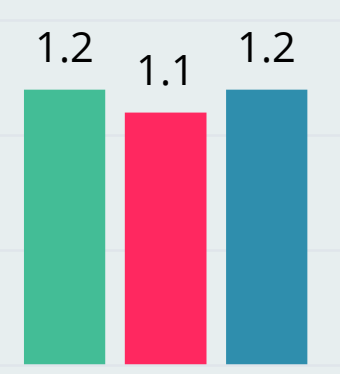

Cannabis $\begin{array}{lll}0.6 & 0.6 & 0.6\end{array}$

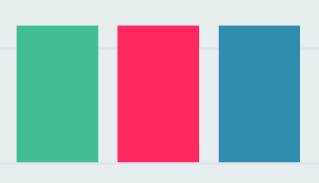

Cocaine

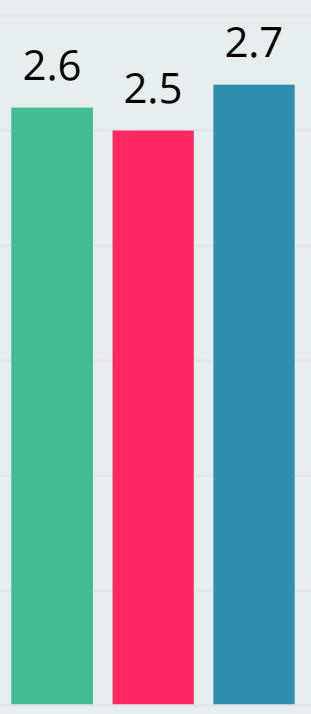

Any NPS

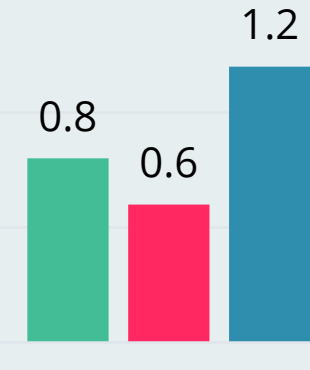

MDMA/Ecstacy

$N=30 K$

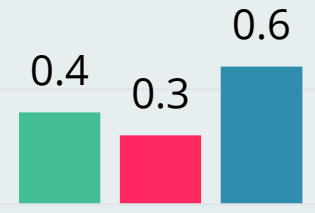

Ketamine

$\mathrm{N}=6 \mathrm{~K}$
4.2

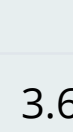

3.6

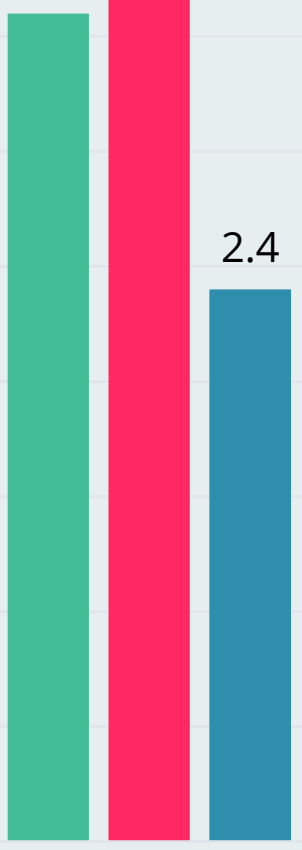

Synthetic cannabinoids

$\mathrm{N}=1.5 \mathrm{~K}$

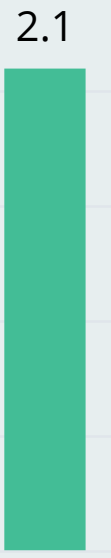

Any substance $n=100 K$ 


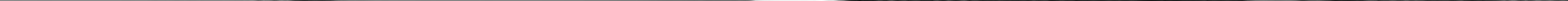


The risk of seeking emergency medical treatment is at least

$30 \times$ times greater after taking

symthetic cannabinoids

$$
\begin{array}{r}
\text { products than } \\
\text { cannabis }
\end{array}
$$

(Winstock et al J Psychopharmacology 2015) 


\section{Comparing synthetic cannabis to high potency herbal cannabis}

Overall synthetic cannabinoids (SCS) can be considered to have a profile that increases the risk of developing both short term and long term problems including dependence. Although at some level it is no longer appropriate to consider SCs as a homogenous class of drugs broadly compared to natural cannabis, those using SCs report the more rapid onset of effects, shorter duration of effects, more rapid development of tolerance and longer, more physical withdrawal, which appears to be occurring at lower levels of use than that seen with natural cannabis. The more pronounced withdrawal is probably due to a combination of the SC products being more potent agonists at the THC receptor than THC (the active ingredient in cannabis) and the absence of a synthetic CBD like molecule which we know balances/reduces both the adverse, acute effects of THC as well as reducing the severity of withdrawal. The addition of synthetic CBD analogues might be one way to ameliorate these unwanted and potentially dangerous risks. More research will need to be done to see if our approaches to managing cannabis withdrawl are sufficient / effective to manage these more aroused states.

GLOBAL

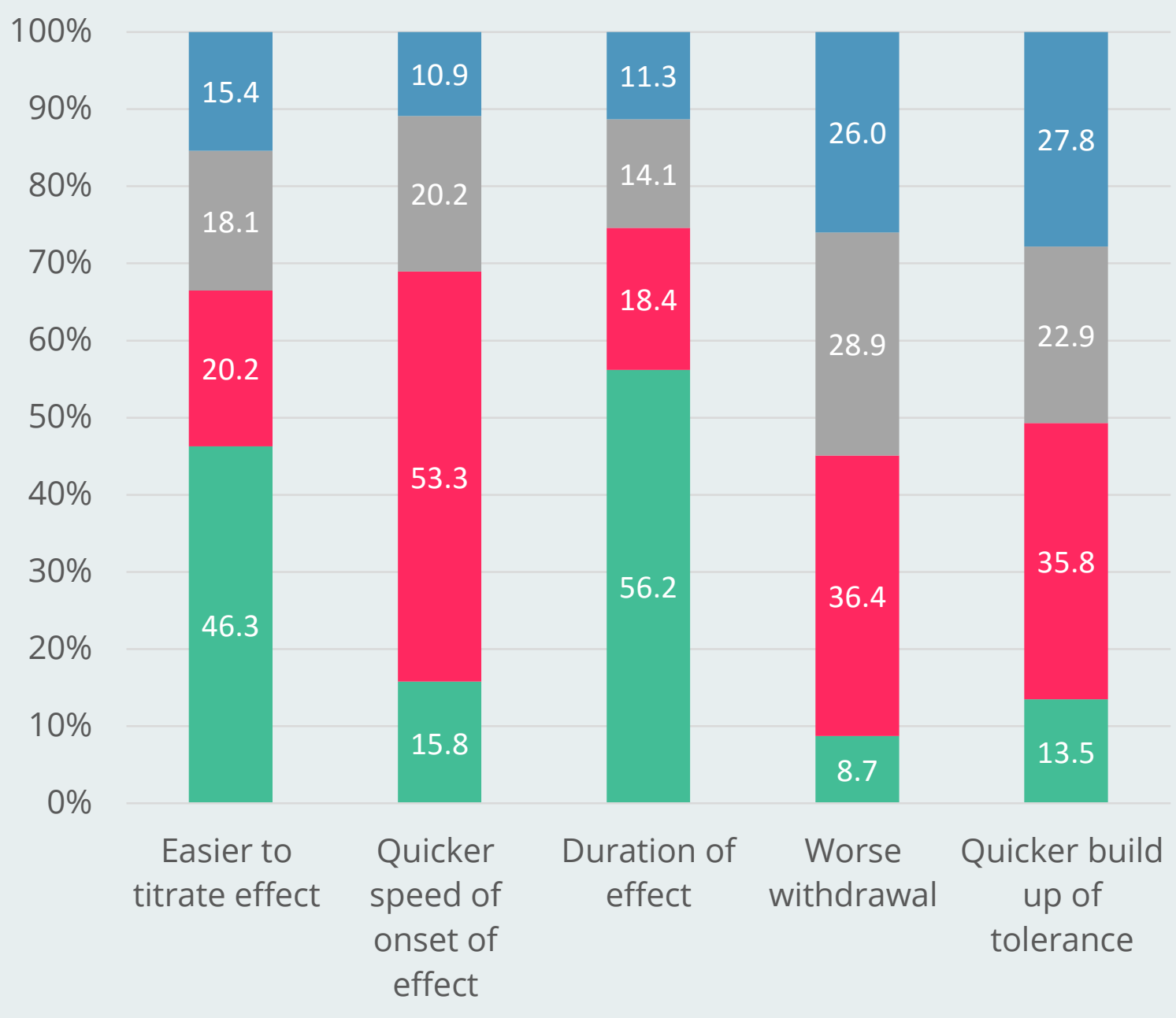

Hi potency herbal Syn Can Same Don't know 


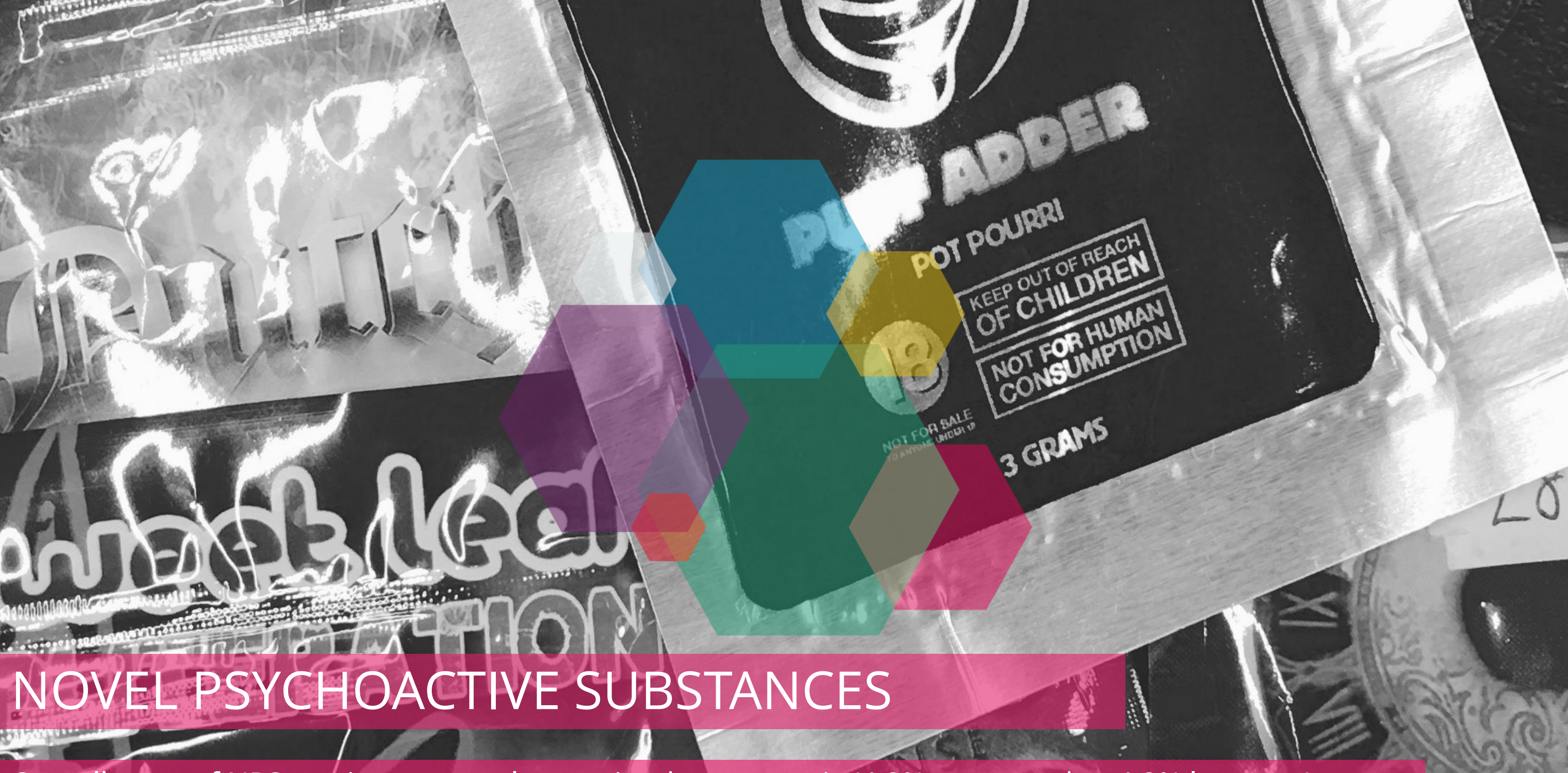

Overall rates of NPS use in our sample remained pretty static (4.8\% compared to $4.2 \%$ last year) there was marked variation between countries in both trends as absolute rates as shown in the next few slides. 


\section{What was the appearance / form of the NPS purchased?}

GDS2016 What was the appearance / form of the NPS used

- GDS2015 What was the appearance /

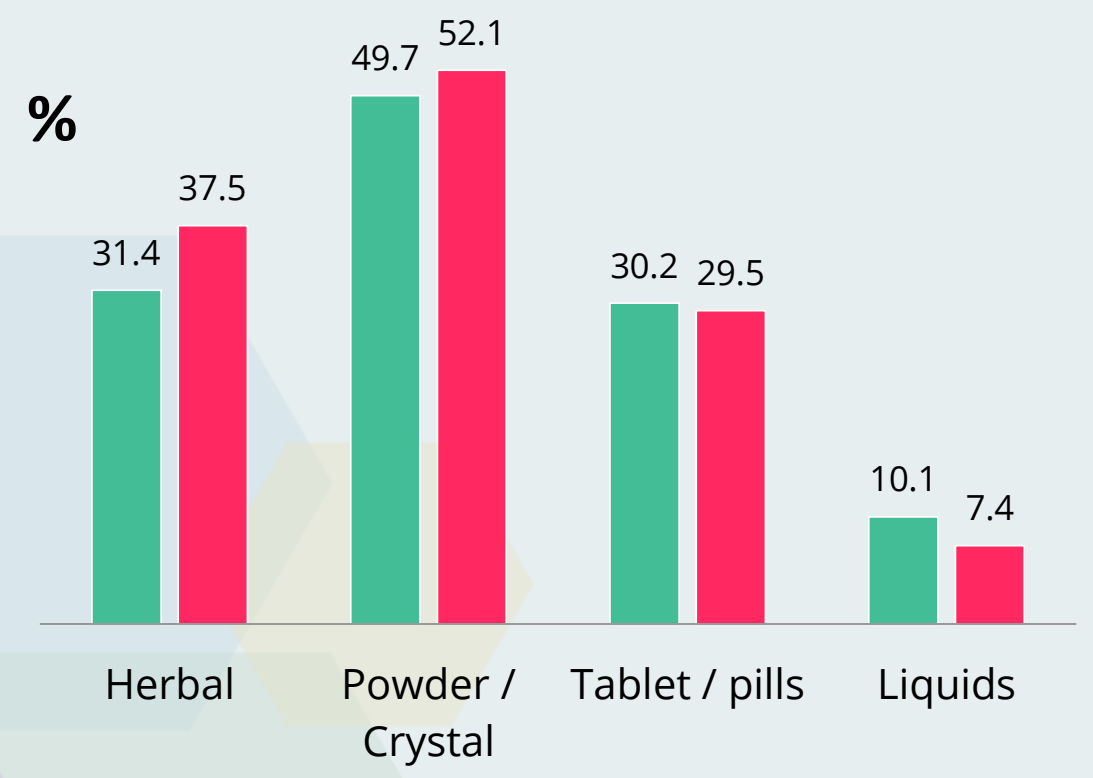

\section{Where did you source them from}

- GDS2016 Where did you get them from? - GDS2015 Where did you get them from?

$$
50.5
$$

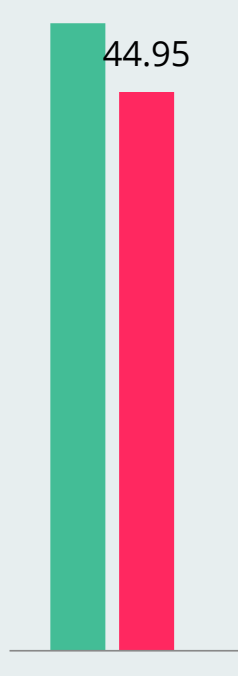

On-line

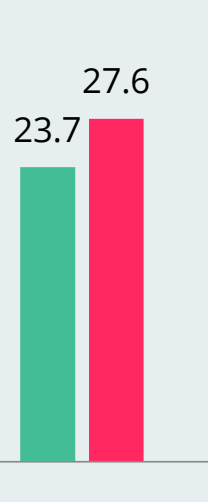

Shop

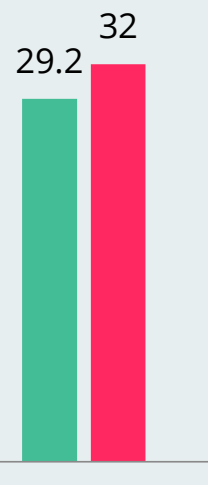

Friend

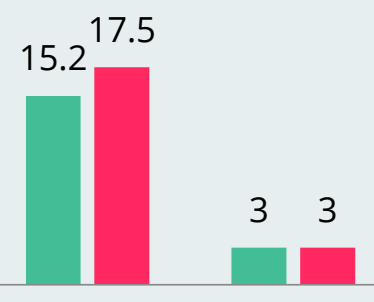

Dealer
Other

GLOBAL

As countries like the UK attempt to ban these new drugs with blanket ban GDS2016 sheds light on what drives the appeal of typically less pleasant drugs and how markets respond to changes in regulation and existing street drugs markets.

The first thing to note is that while national legislation might reduce access on the high-street, globally and indeed in most countries the most common place where people purchase NPS is online. 


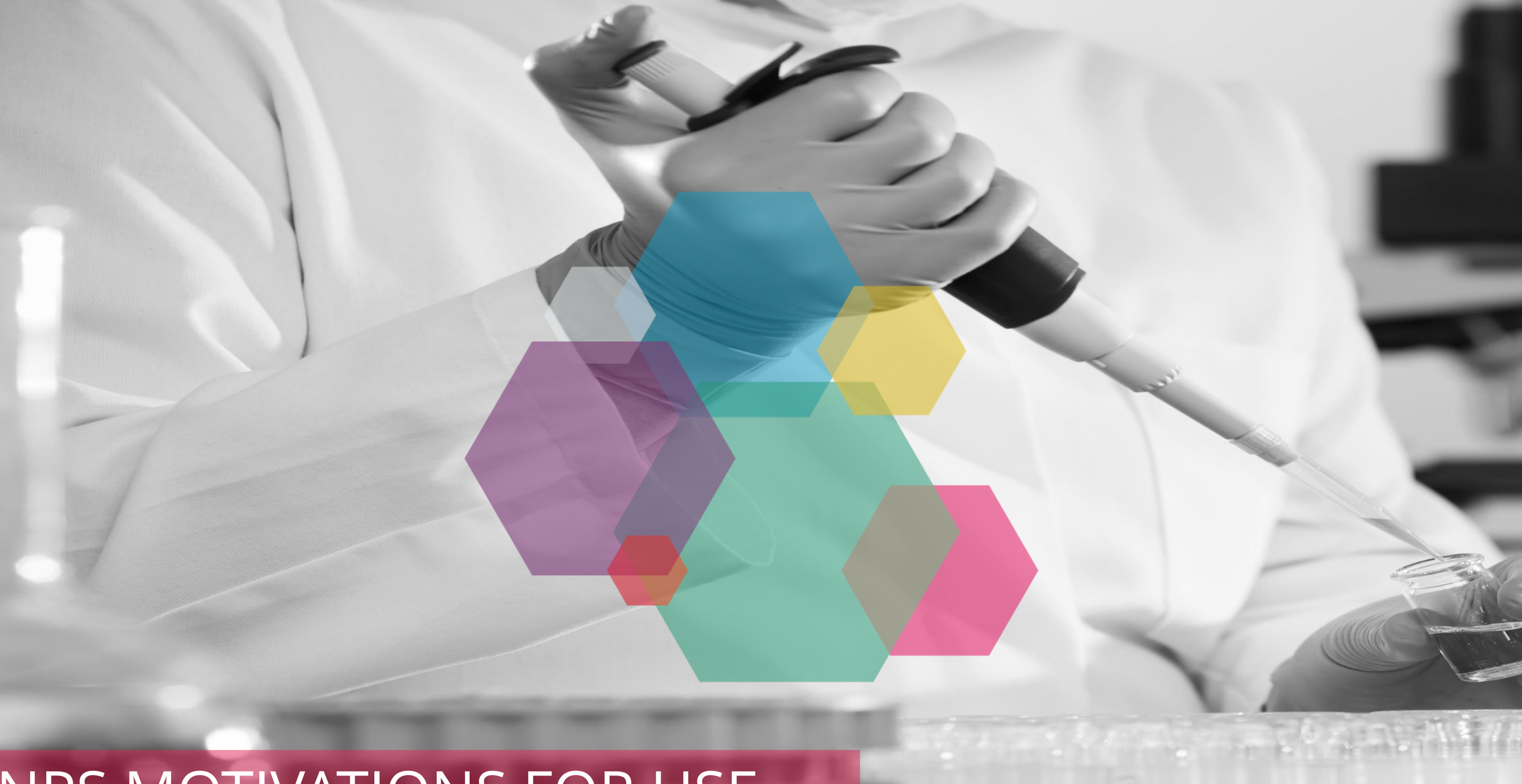

NPS MOTIVATIONS FOR USE 
The Novel Psychoactive Market / Research Chemical market appeared in the late 2000s on the back of a decline in purity of traditional stimulants (MDMA in particular).

4 years go when we asked about motivations for their use - the nonavailability of other drugs and their poor quality was cited as the major factor. As the quality of traditional drugs has improved in recent years the motivators have changed and now perhaps there is greater importance on perceived value for money and ease of access on line.

What is clear from all the GDS surveys and publications is that NPS generally do not have an effect profile that is preferred to traditional drugs by the vast majority of users and and very importantly they are not seen as safer than traditional drugs. So the media narrative suggesting that most people think just because drugs are legal they are safe - is not true - it is not supported by the evidence.

This year we asked over 4500 people who had used a variety of NPS in the 12 months prior to the survey how important various factors were in motivating their decision to use what their main motivations for using these drugs were. Alongside findings from GDS2016 we also provide the results from GDS2015.

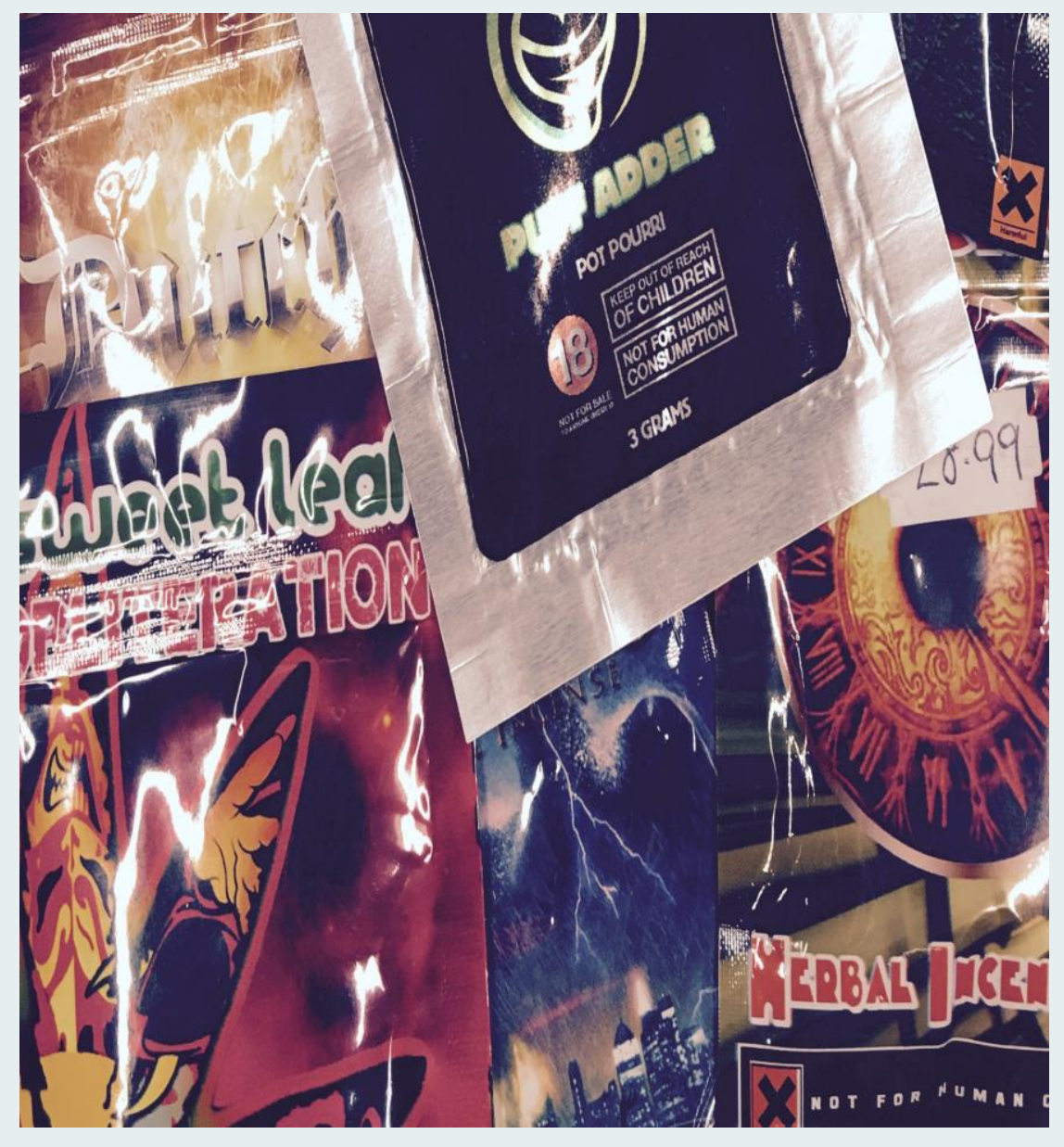

Why would people buy drugs that are more dangerous and have a less nice effect profile? 
This section focuses on answers of 79,040 study participants who reported illegal drug use and who answered at least one of the four "desert island drugs" questions.

Recent discussions about the motivations for the use of new psychoactive substances (NPS) and increasing NPS use in certain countries who participated in previous Global Drug Surveys made us carry out a thought experience. What would be the preference of recreational drug users if all commonly used drugs were freely available? Would they still be interested in the use of NPS or would they be satisfied with the commonly used drugs? We designed a hypothetical situation and asked the following questions:

Imagine you are shipwrecked on a desert island. Cannabis grows wild and magic mushrooms (not poisonous ones) cover the island. By chance there is also a plentiful supply of high purity MDMA and powder cocaine. Alcohol is easily accessible too.

A genie comes along and says you can exchange any of these for any new syntheticversion of these drugs in the world.

\section{Can any NPS compete with traditional illicit?}

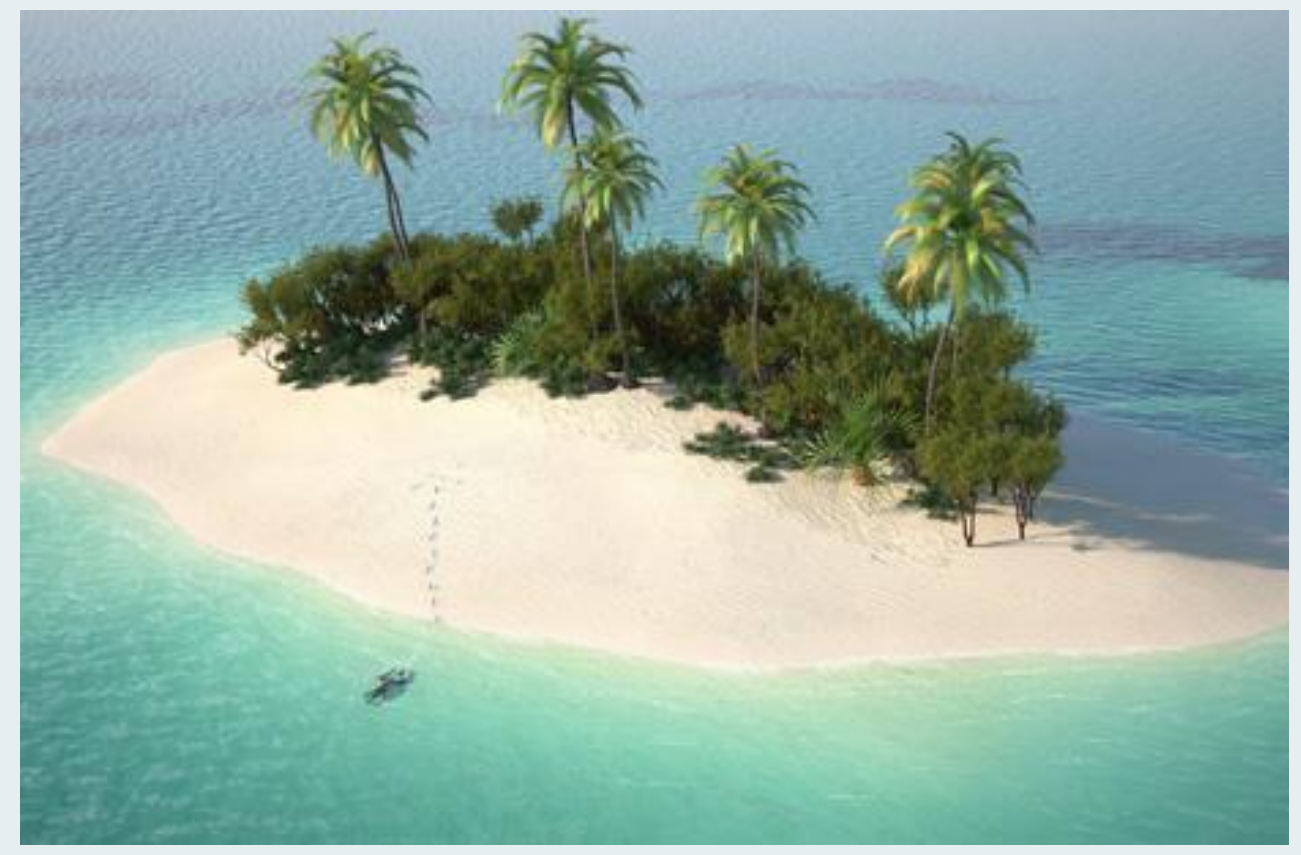

The genie asks if they would exchange?

Cannabis for synthetic cannabis

Cocaine for a synthetic stimulant

MDMA for a another synthetic drug with similar effect

Magic mushrooms (excluding LSD) for a synthetic

hallucinogenics

Options: yes / no / unsure / don't care /not interested in this drug 


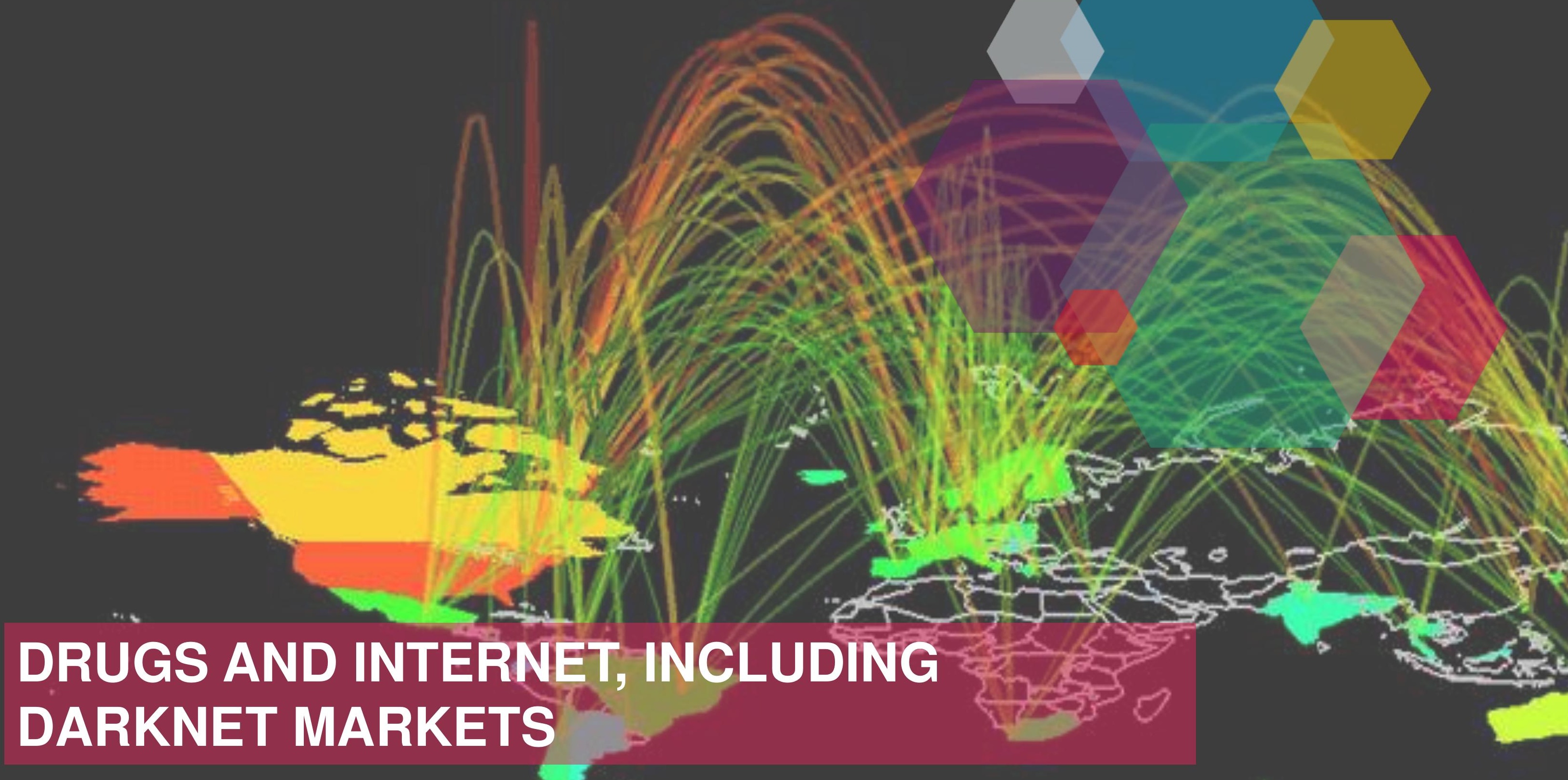


Darknet markets or cryptomarkets have now been operating for 5 years (since the launch of Silk Road in February 2011). In the deep web, site owners, vendors and buyers are able to remain relatively anonymous as their IP addresses are masked. Purchases are made using the decentralised virtual currency Bitcoin, which can also be used relatively anonymously.

Our work on dark-net markets or crypto-markets is already some of the most cited in the world and working with leading researchers in the field like GDS's own Dr Monica Barratt we've continued to tell the story of the biggest challenge to drug laws and their enforcement in a century.

GDS2016 occurred 2 years after the demise of the original Silk Road and 1 year after Operation Onymous which brought down a number of cryptomarkets that had arisen as replacements. Exit scams, where market owners close the market unexpectedly and steal the funds, have become commonplace. Despite these disruptions, we have obtained a record sample of darknet drug buyers in GDS2016 (n=8058).

Drugs have also increasingly been bought through the internet more generally, including 'normal' websites and through social media, as reflected in our annual question about internet drug buying. GDS has once again conducted the biggest survey of dark-net involvement ever done and our findings suggest that like other areas of e-commerce it is here to stay. And our findings show that year on year more and more people are shopping on the dark-net. The following two graphs show how samples from most countries where we have the largest number of respondents reported greater rates of darkGLMebbuying compared to previous years, with the highest rates in the UK, US and Ireland. 


\section{Three year trends: recent darknet market use}

Recent darknet market use includes purchasing their own and getting someone to purchase on their behalf in the last 12 months. Base: respondents reporting use of illicit/NPS/prescription drugs in the last 12 months.

Only countries with $\mathrm{N}=500+$ in all 3 years are included.

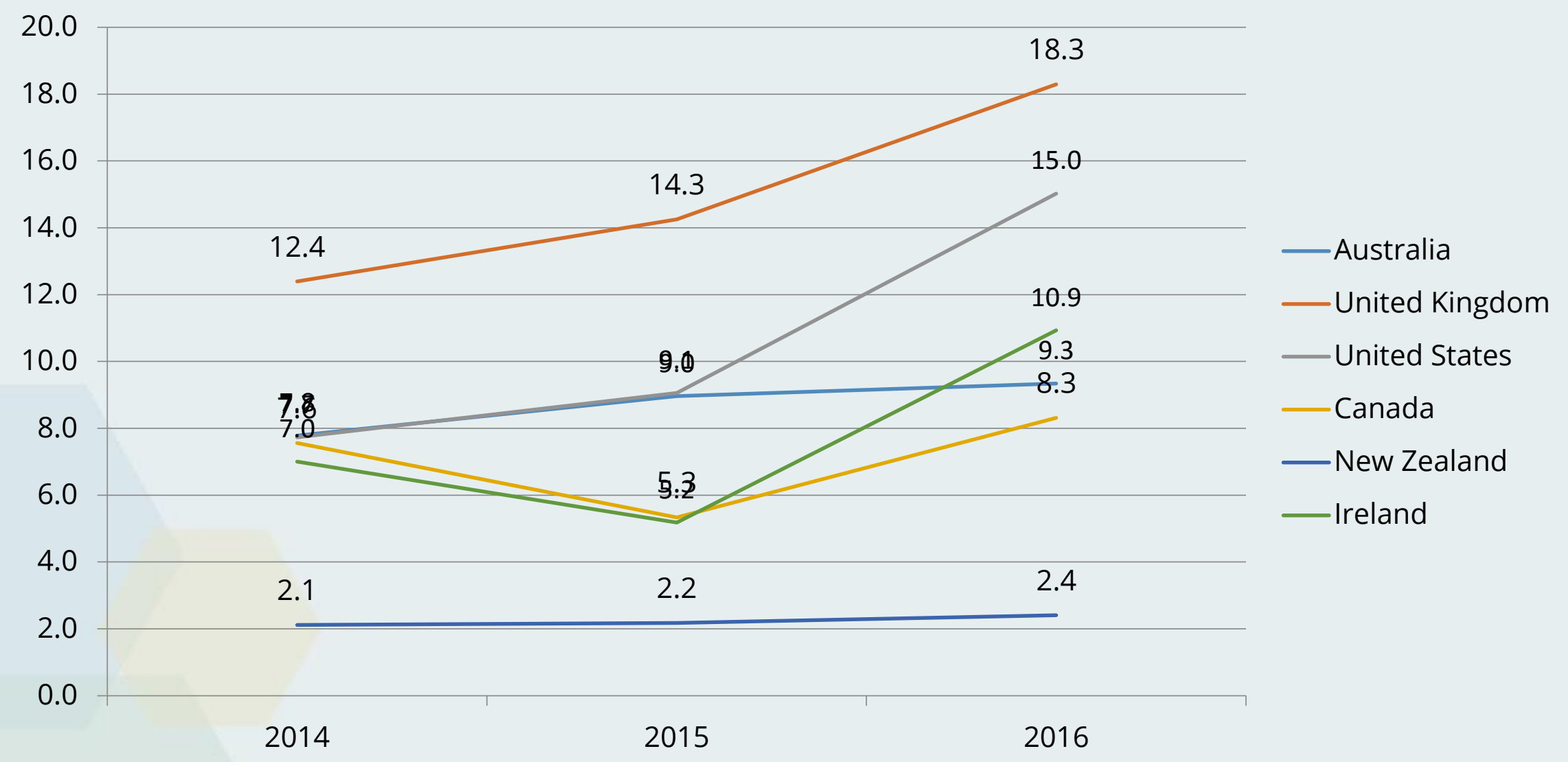

\section{English-speaking} countries:

- Increases can be seen between 2015 and 2016 in UK, Ireland, US, Canada.

- Stable in Australia and New Zealand

- Changes in rates across years and differences in rates between countries could be explained by sampling differences 


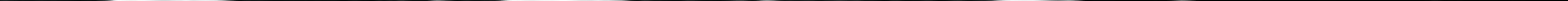


How much: How many : Amount of cocaine used in a session \& mean number of lines / gram

Mean number of grams used per session

Mean number of lines per gram

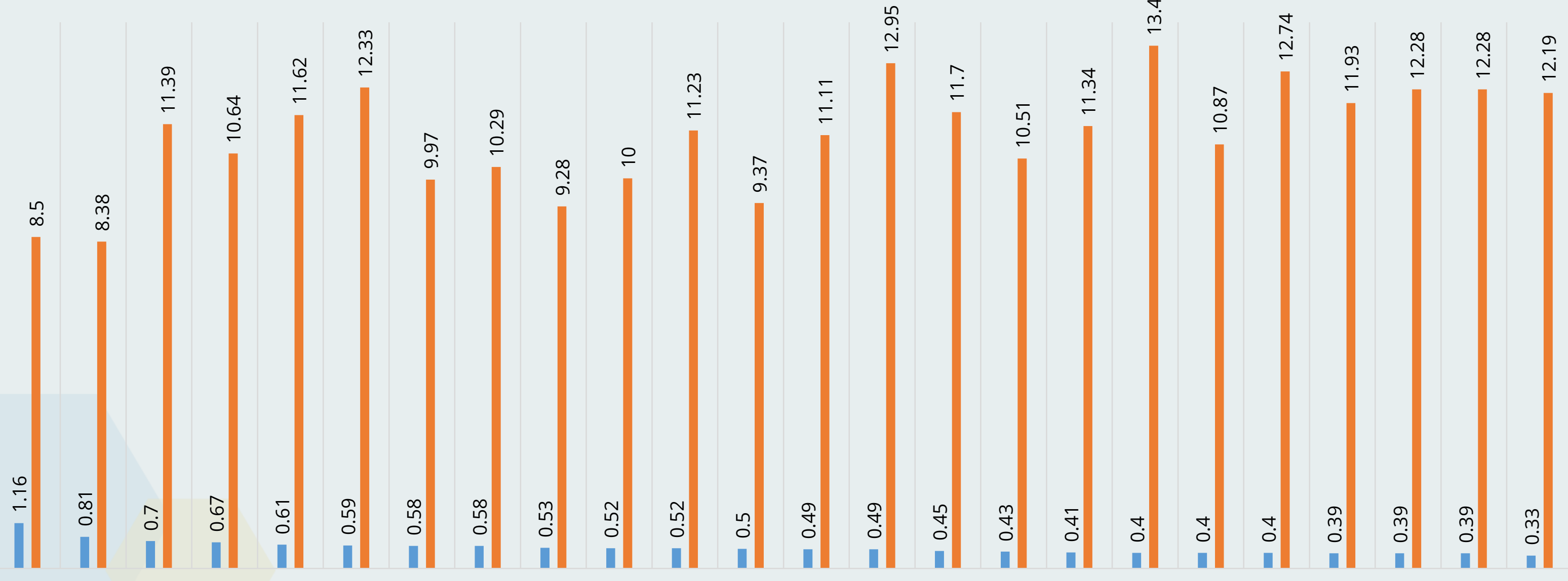


GDS2016 asked participants to rate drugs based on their value for money from 1-10 (1=poor value for money $10=e x c e l l e n t$ value for money).

10

mean value for money score based on global sample

9

8

7

6.8

7

7
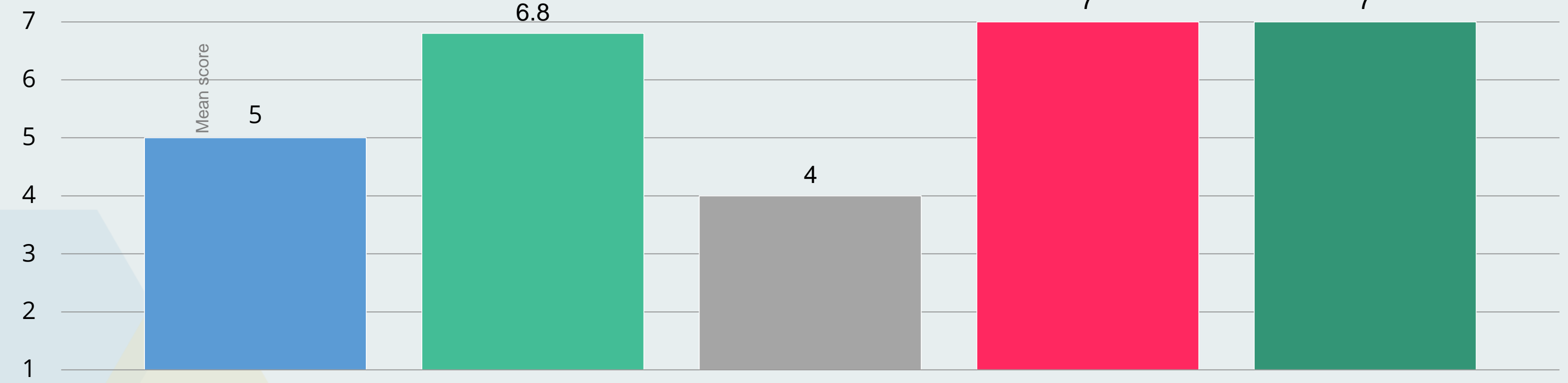

Global

Alcohol

Cannabis

Cocaine

MDMA Pills

- MDMA Powder 



\section{PILLS CONTAIN MORE MDMA}

THAN EVER BEFORE 
2016 might be the worst time to start taking MDMA in a generation. MDMA has never been so plentiful and as GDS trend data shows, more and more people are using it. The rising popularity of EDM and dispersion of MDMA from the dance floor to mainstream drug culture has coincided with resurgence of MDMA availability. In many countries high purity MDMA crystal now competes with high dose MDMA pills (in many parts of Europe the average dose of MDMA found in ecstasy pills is now 100-150mg/pill with doses over 300mg having been reported). But odd as it might seem better quality drugs are not necessarily safer for users (especially if you don't know what you're taking). Higher dose preparations and high purity powders can make it more difficult to dose safely and it can be easy to take too much.

Data from over 50,000 ecstasy users collected as part of GDS2015 and GDS2016 suggest that just under 1\% of ecstasy users sought emergency treatment following the use of pills and powders sold as MDMA in the previous 12 months. Young women seem more likely to present than men (unrelated to body size or consumption patterns) with a rate 2-3 times higher than men. At the time of writing in mid-2016, the drug that causes the most issues in things sold as MDMA or ecstasy is still, in most cases, MDMA itself. While drug checking has a role to play, just knowing what's in your pill or powder does not make it safe.

In the wake of the UK Government's ban on everything that gets you high, one consequence might be more people returning to traditional drugs. It seems to GDS that better quality drugs need better quality drugs education (actually rubbish drugs need better education as well). 


\section{TAKING TOO MUCH HAS NEVER BEEN SO EASY}


GDS2016 \% of last year users of each substance who sought Emergency Medical Treatment

NEWS

YOUNG WOMEN

MOST AT RISK

FROM ECSTASY

1.4

1.2

1

$\stackrel{\frac{\infty}{\omega}}{\underline{m}}$

$\stackrel{\mathscr{Q}}{\stackrel{9}{3}} 0.8$

ळ

亗 0.6

。

0.4

0.2

0

\section{HOSPITALISATION}

Females most at risk from strongerthan-ever pills following the use of *MDMA

$(n=30,000)$

*not just clubbers

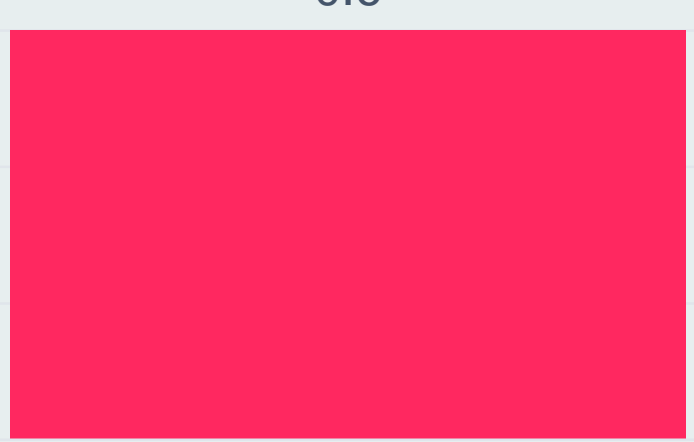

MDMA/Ecstacy

- Global Male Female 


$$
\text { DON'T BE DAFT }
$$

START WITH HALF

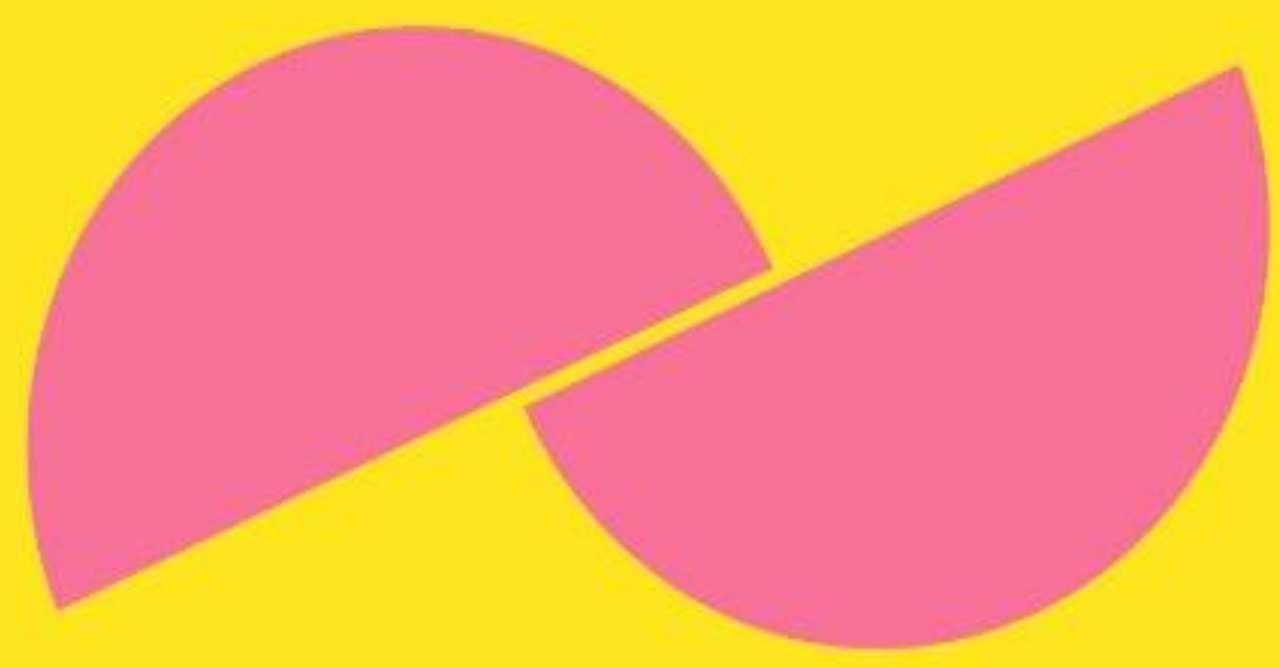


If you found this report interesting and want to know what else we can offer please e-mail us at info@globaldrugsurvey.com

Please also take just $\mathbf{5}$ minutes to take part in the first ever GDS mini survey at www.globaldrugsurvey.com/GDS2016.5 where will explore drug-vaping, drug checking, what to do if you mate passes our and the use of psychedelics.

GDS2017 launches in November 2016 if you would like to take part or help promote it in your country please contact us.

Until then have a safe happy summer

Dr Adam R Winstock

On behalf on the Global Drug Survey team everywhere adam@globaldrugsurvey.com

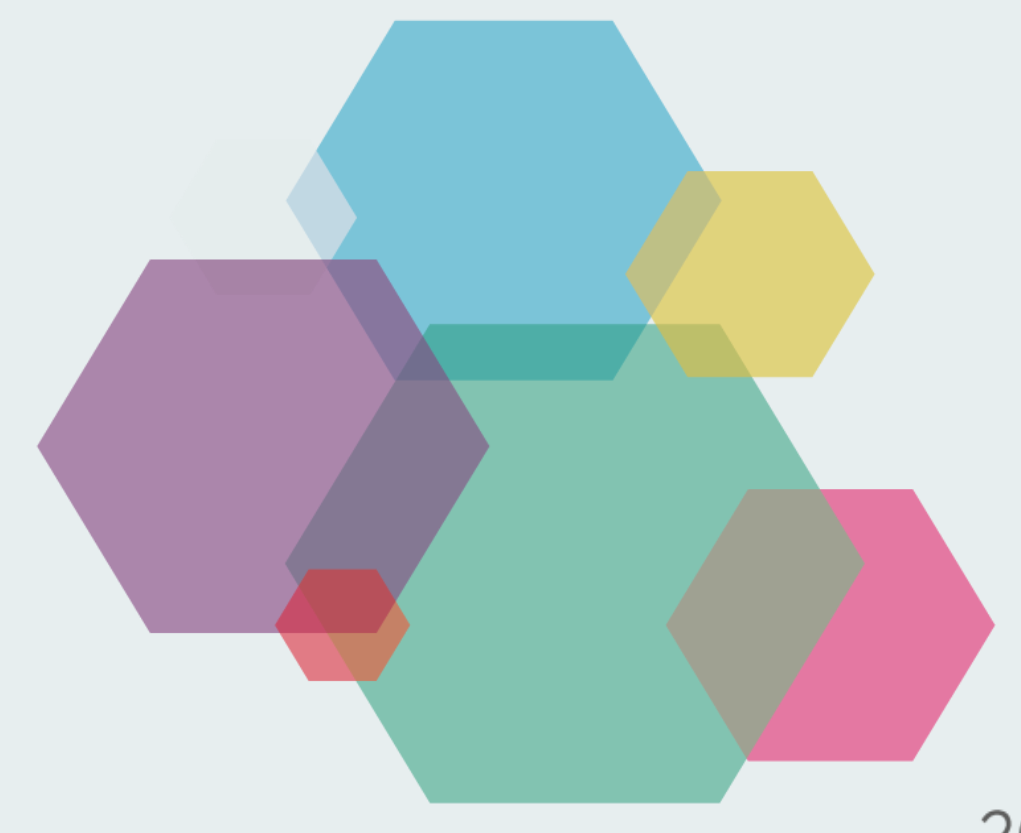

